\title{
Electrochemical Detection of 4-Nitrophenol by Using Graphene Based Nanocomposite Modified Glassy Carbon Electrodes: A Mini Review
}

\author{
E. Prabakaran, Kriveshini Pillay* \\ Department of Chemical Sciences, University of Johannesburg, P.O. Box 17011, Doornfontein, Johannesburg 2028, South Africa \\ Email: kriveshinip@uj.ac.za
}

Received: 17 December 2020; Revised: 22 February 2021; Accepted: 28 February 2021

\begin{abstract}
This article describes the fabrication of electrochemical devices for the detection of a key environmental pollutant, 4-Nitrophenol (4-NPh). 4-NPh is a requirement for the synthesis of organophosphate pesticides. These pesticides are mostly used in the agricultural sector to obtain a high yield of agricultural products. The use of 4-NPh in the agricultural field results in poisonous levels of this compound in the soil and water. Different techniques have been used for its transformation by biological and chemical degradation. However, these strategies not only created highly toxic pollutant but also need fast operation and time consuming processes. In this background, we have reported a broad and efficient review of the electrochemical reduction of 4-NPh as a feasible alternate method. In this review paper, graphene oxide (GO), reduced graphene oxide (rGO), N-doped graphene oxide, functionalized graphene oxide, metallic nanoparticles coated graphene oxide, metal oxides covered on rGO, polymer functionalized graphene oxide and hybrids materials functionalized with graphene oxide (hydroxyl apatite and $\beta$-cyclodextrin) which have been fabricated on a glassy carbon electrode (GCE) to enhance the electrocatalytic reduction and increase the sensor activity of 4-NPh are discussed. We have also described the effects of a few interfering phenolic pollutants such as aminophenol, hydroquinone, o-nitrophenol (o-NPh), trinitrotoluene, trinitrophenol, 2, 4-dinitrophenol (4-DNPh) and nitrobenzene. In the paper, easy and more effective electrochemical methods for the detection of 4-NPh with graphene- based nanocomposites modified on GCE for 4-NPh detection are summarized and discussed.
\end{abstract}

Keywords: graphene nanocomposite, electrochemical sensor, 4-Nitrophenol

\section{Introduction}

Hazardous pollutants result in a polluted environment and have an effect on humans and other living organisms [1-2]. A huge amount of toxic heavy metals are present in soil, water, air and plants. These toxic heavy metals are incorporated into food chain, biomagnify into food and effectively result in severe health effects [3]. Nitrates, ammonia, phosphates, salinity and electrical conductivity were used to manufacture fertilizers and are comparable with other fertilizers on the market. Microalgae and macrophytes removed $4.4 \%$ of the chemical organic demand (COD) when compared to nitrates $(12.5 \%)$, ammonia (11.3\%) and phosphates $(70.47 \%)$. The nitrates, ammonia and phosphates were compared with other common fertilizers removing of $95 \mathrm{mg} / \mathrm{g}, 39.5 \%$ and $62.5 \%$, respectively. L. minor was used in the preparation of fertilizer and L.minor and C.inerta were used to eliminate organic pollutant nutrients from palm oil mill effluent (POME) [4]. Pyrene was degraded by fungi to isolate new species to biodegrade remazol brilliant blue R (RBBR).

Copyright (C2021 Kriveshini Pillay, et al.

DOI: https://doi.org/10.37256/nat.222021750

This is an open-access article distributed under a CC BY license

(Creative Commons Attribution 4.0 International License)

https://creativecommons.org/licenses/by/4.0/ 
The biodegradation method has been developed with various parameters like agitation, concentration of glucose, temperature and salinity [5].

Environmental pollution is fashioned by means of the release of natural compounds waste from industries and a variety of dangerous wastes have contaminated the soil and water [6-7]. Consequently, the monitoring of pollutants is very important in soil and water and protects the surroundings from dangerous waste. The removal of organic compounds is very challenging to maintain water and soil resources. Even though, sensor methods have provided a good means of environmental protection such as water and soil [8]. However, simple and low-cost sensors for the evaluation organic pollutants such as nitrophenols $(\mathrm{NPh})$ in water are needed [9]. Nitrophenols are toxic pollutants in human and animals. Nitrophenols are very crucial chemical substances for the manufacturing of pesticides, pigments, rubber chemical compounds, explosives and prescribed drugs [10]. They are continuously bleaching soil and damaging water environments, so in this sense they are among the foremost toxic chemicals [11]. Nitrophenols possess different properties such as they are toxic, inhibitory and bio-refractory natural chemicals. Amongst them, 4-NPh is the most important toxic and hazardous chemical that is detrimental to the health of living organisms in both soil and water environments [12]. If 4-NPh is continuously inhaled it causes health issues such as nausea, cyanosis, complications in humans and the Environmental Safety Corporation indexed and restricted its concentration to $0.43 \mu \mathrm{M}$ in water environments [13-14]. Most fertilizers manufacturing industries use 4-NPh for the production of insecticides in agricultural use and act as intermediate compounds in fertilizers [15]. The plastic, paper, dyes, rubber industries are also major contributors to the presence of this pollutant in the environment. The effluents of these industries therefore contain small amounts 4-NPh which is released into the environment [16-18]. Despite the fact that, a low amount of 4-NPh is present in soil and it still can cause diseases in humans and residing organisms. 4-NPh is without difficulty highly stable in the environment [19-22]. 4-NPh which is present in industrial wastewater, home wastewater and agricultural wastewater can cause infections in humans and other living organisms as shown in Figure 1.

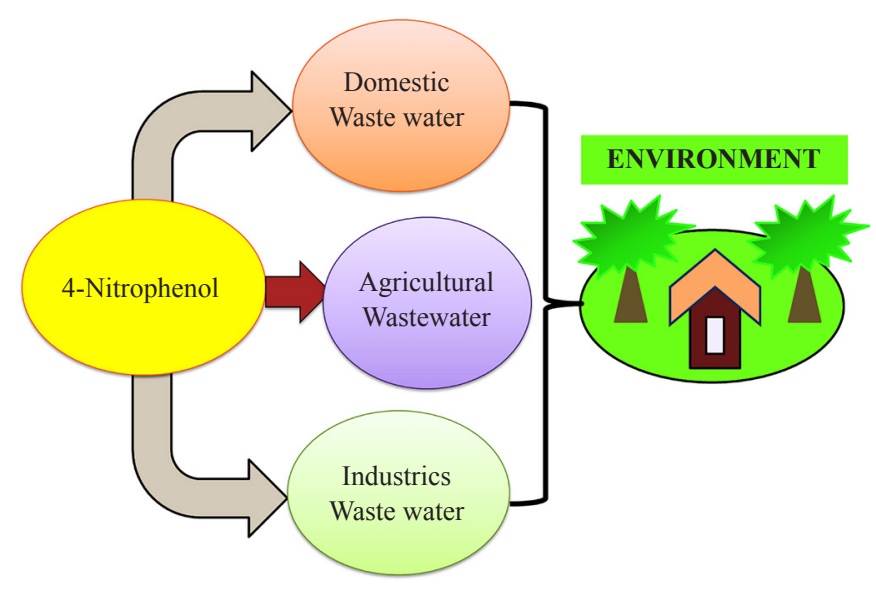

Figure 1. 4-NPh discharged into environment from industrial waste water, domestic waste water and agricultural waste water

Numerous techniques have been explored for the complete oxidation of 4-NPh such as biodegradation [23], microbial catabolism [24], Fenton reagents [25], photocatalytic degradation [26] and electrochemical techniques [27]. However, these methods can make different aromatic compounds like p-benzoquinone, 4-nitrocathechol, hydroquinone and phenol and they have shown higher toxicity than 4-NPh [28-29]. Recently, the degradation of 4-NPh has been performed by a chemical reduction method. However, the chemical reduction method is used with good reducing agents and is more toxic than transition metals [30]. Furthermore, the chemical reduction technique needs high power operating conditions for the degradation of 4-NPh [31]. Electrochemical reduction of 4-NPh is a better alternate method for eliminating hazardous pollutants and it also produces toxic byproducts. The intermediate products are used in different chemical industries and are used in various applications [32-33]. Therefore, electrochemical reduction techniques can be applied for the electrochemical degradation of 4-NPh into 4-Aminophenol (4-APh) and it was also shown to be easy and 
less time-consuming for the reduction of 4-NPh into 4-APh.

In this review article, we have therefore focused on the electrochemical reduction of 4-NPh with various experimental procedures. The effective reduction of 4-NPh was conducted with various modified glassy carbon electrodes (GCE). Different graphene based modified GCE electrodes have been reported for the electrocatalytic reduction of 4-NPh.This review also discusses the modification of GCEs with some phenolic compounds with graphene based nanocomposites by electrochemical processes. Generally, effective and simple electrochemical processes for the reduction of 4-NPh by GCEs modified with graphene are discussed.

\section{The major uses of 4-NPh}

4-NPh is widely utilized in the pharmaceuticals, insecticide, explosive and dye industries [34-36]. The majority of 4-NPh arises from the manufacturing of fertilizers like organophosphorus. Organophosphorus acts as an insecticide which includes parathion, methyl parathion and methamidophos and they are all poisonous agricultural chemicals create severe damages to humans, plants and other living organisms. 4-NPh is used as an intermediate to produce herbicides and pesticides. This has rendered it a major pollutant in water and is effortlessly soluble in water which also results in it becoming a cancer causing agent [37]. Pesticides also create problems for humans and plants and their 4-NPh intermediate has also created problems in the environment. The European environmental agency has set the maximum permissible limit of $0.1 \mathrm{~g} / 1$ for pesticides in drinking water [38]. 3-methyl-4-NPh, 4, 6-dinitro-ocresol, parathion-methyl, fenitrothion are examples of compounds containing the 4-NPh intermediate and they are used in vegetation (wheat, corn and potatoes). These compounds enter the surface of water and sedimentations and they are able to easily persist in water [39]. These derivatives of 4-NPh are without problems soluble in drinking water [40]. The proposed mechanism for the conversion of of organophosphate into 4-NPh is shown in Figure 2.

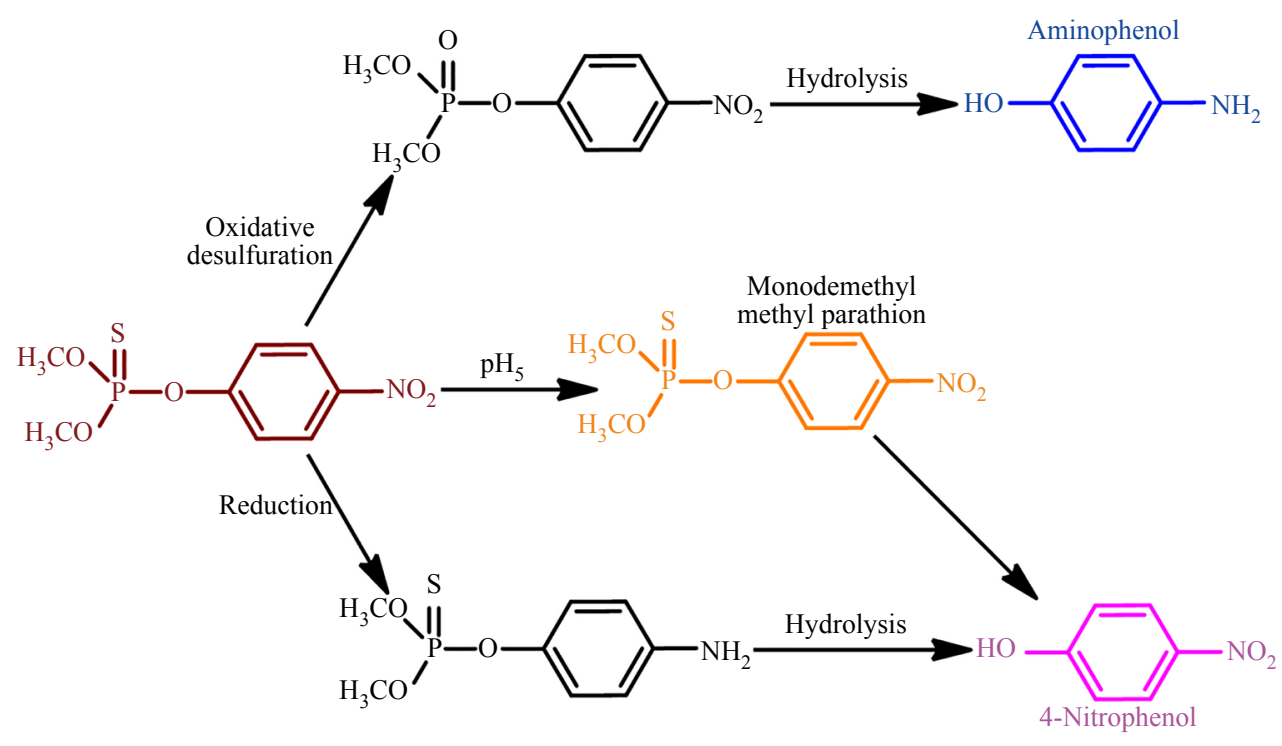

Figure 2. The proposed mechanism path ways of organophosphate to 4-NPh

\section{Analytical methods for 4-NPh detection}

In the last ten years, different analytical methods have been recognized and used for the sensing of 4-NPh as shown in Figure 3. These methods include Capillary electrophoresis [41], High-Performance Liquid Chromatography [42], Spectrophotometry [43], Float-injection analysis [44] and Enzyme-related immune sorbent assay [45]. Even though, most of the analytical methods are expensive and demand longer time analysis, these drawbacks can be overcome. 
Electrochemical methods are becoming increasingly popular for the detection of 4-NPh. The electrochemical approach offers the advantages of low cost, easily handling, good sensitivity and selectivity and in-situ detection [46-47]. The electrochemical analysis of 4-NPh using a bare GCE offers lower sensitivity, excessive over potential and interference problems [48]. Therefore, modified GCEs have been used to solve these problems and to improve the electrochemical detection of 4-NPh [49-51].

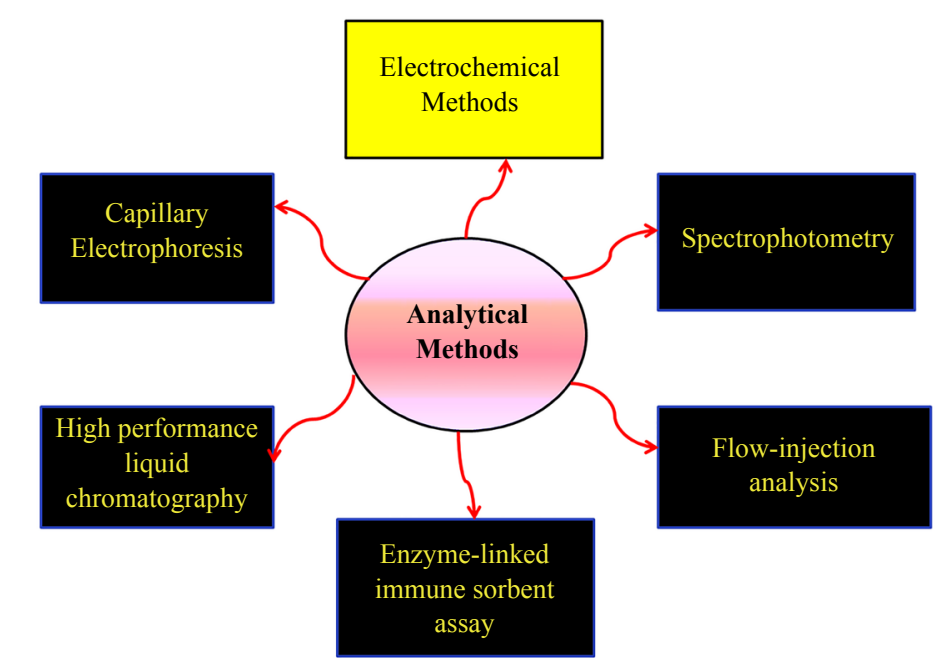

Figure 3. Analytical methods for the determination of 4-NPh from wastewater samples

\section{Electrochemical sensor principle}

The electrochemical sensor is referred to as a growing chemical sensor in analytical chemistry. A chemical sensor has without difficulty been incorporated into devices and provides additional information on the environment. This sensor has also been validated to directly identify the chemical substances in environmental samples. Such sensors are also able to identify the physical state of the analyte [52]. The electrochemical sensor is a crucial device because of its excellent delectability simplicity, low cost and easy operation and it can be also used to analyse a wide variety of samples including industrial, clinical, environmental and agricultural samples. Electrochemical sensors can be divided into three types which include Potentiometric, Conductometric and Amperometric. The Potentiometric sensor works on the principle of equilibrium between the sensor interface and sample potential. The signal is measured between two electrodes. Conductometric sensors measure the conductivity of the sample with collection frequencies. An Amperometric sensor measures the potential of the sample between the reference electrode and working electrode for the duration of oxidation and reduction of samples and subsequently gives a current reading as a signal. The electrochemical sensor is consequently becoming more popular in Analytical Chemistry [53-57].

The chemically modified GCE has demonstrated a greater ability for the detection of 4-NPh than the biologically modified GCE. The biological substrate does not give a good signal and demonstrates poor sensing due to fouling and the formation of an electrochemical polymerization film on the GCE [58]. Electrochemical sensor applications in biological samples include the detection of ascorbic acid, dopamine, glucose, hydrogen peroxide and metallic ion sensing via using the chemical sensor [59]. Electrochemistry converts an electrical sign into a digital signal for the detection of the analyte as shown in Figure 4. Typically, the cyclic voltammetry approach has produced the signal from chemical substrates and electricity and the associated signal is likewise associated with Linear Sweep Voltammetry, Potentiometric, Amperometric and Conductivity measurements [60]. The important processes of the electrochemical sensor have enhanced the electrocatalytic properties, sensitivity, selectivity and interference. 


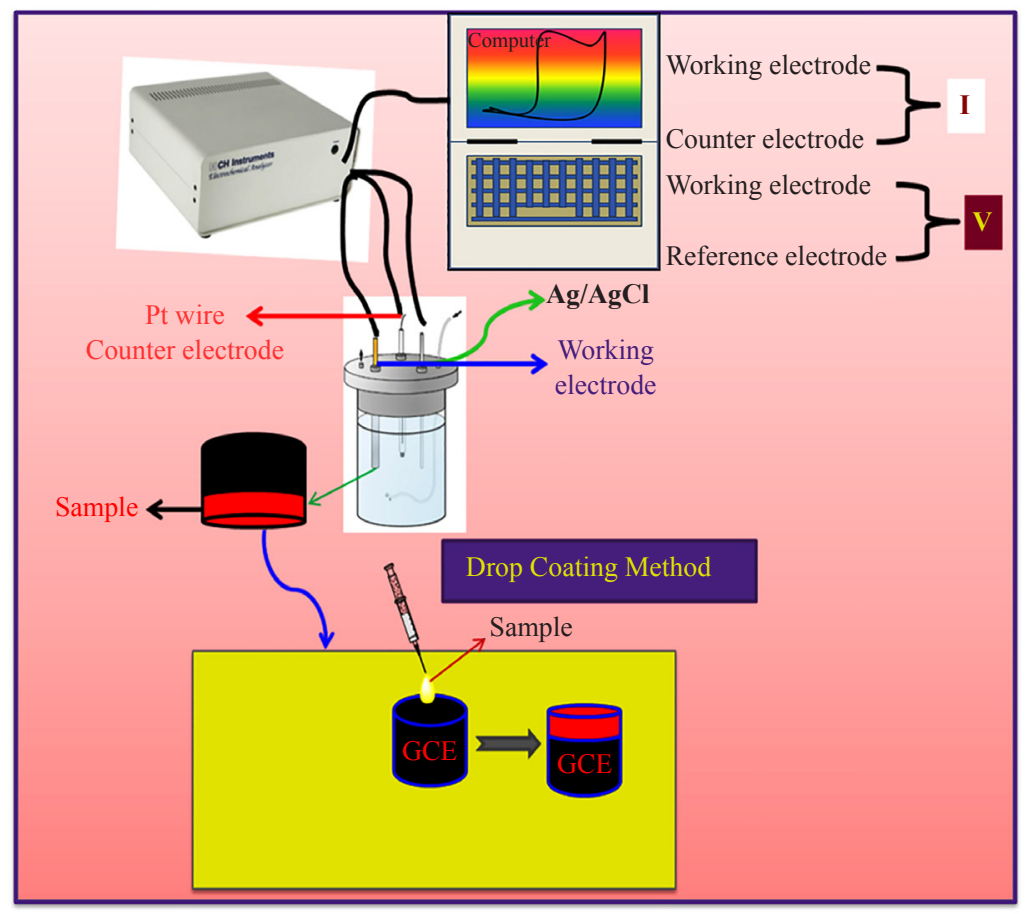

Figure 4. Principle and modified route in the function of an electrochemical application

\section{Electrochemistry of 4-NPh}

Generally, 4-NPh has electrochemical properties that lead to the electrocatalytic reduction of 4-NPh to 4-APh at a GCE. At the electrode surface 4-electrons and 4-protons are transferred resulting in the conversion of 4-NPh into hydroxyl aminophenol an intermediate compound [61-62]. Further, the hydroxyl aminophenol is reduced to benzoquinone imine and the elimination of water occurs after which the final product of aminophenol is acquired from benzoquinone imine by the intermediate of hydroxyl aminophenol [63-64]. The electrocatalytic reduction mechanism of 4-NPh into 4-APh is proposed. But, the floor amendment technique on the electrode has solved the problems including poor kinetic rate of the modified electrode and excessive overvoltage potential. This is an essential technique for boosting the sensitivity and selectivity of 4-NPh [65].

\section{Different modified electrodes for 4-NPh}

Electrochemical detection of 4-NPh has been performed with different GCE sensors by various electroactive nanomaterials. These nanomaterials include metallic nanoparticles, metallic oxides and metal oxide nanocomposites, polymer nanocomposites and carbon nanocomposites. Metallic nanoparticles are mainly silver nanoparticles [66] but bimetallic Au-CuNPs nanoparticles have also been applied for the electrocatalytic conversion of 4-NPh [67]. ZnONPs, $\mathrm{CuONPs}, \mathrm{Cu}_{2} \mathrm{ONPs}$, Alpha- $\mathrm{MnO}_{2} \mathrm{NPs}$ and $\mathrm{Fe}_{3} \mathrm{O}_{4} \mathrm{NPs}$ have been utilized as modified electroactive materials in the detection of 4-NPh [68-72]. Chitosan nanocomposites, polyaniline nanocomposite, poly (p-aminobenzene sulfonic acid) nanocomposites and poly(methylene blue) nanocomposites have also been applied for the electrocatalytic reduction 4-NPh [73-76]. The carbon substances and metallic nanoparticles composites include CNTs, AgNPs/CNT, Mesoporous, Graphene oxide (GO), molecularly imprinted Graphene, AgNPs/rGO, AuNPs/rGO, $\mathrm{MnO}_{2} \mathrm{NPs} / \mathrm{GO}, \mathrm{RGO} / \mathrm{PSA}$ and GO-Chit as shown in Figure 5 [77-87]. The electrochemical methods include Cyclicvoltammetry, Linear Sweep Voltammetry, Differential Pulse Voltammetry, Square Wave Voltammetry (SWV), Amperometry and Impedance Spectroscopy and all of these methods have been used for the detection of 4-NPh. Different nanomaterials have been classified for the electrocatalytic reduction of 4-NPh as shown in Table 1 [88-102]. 


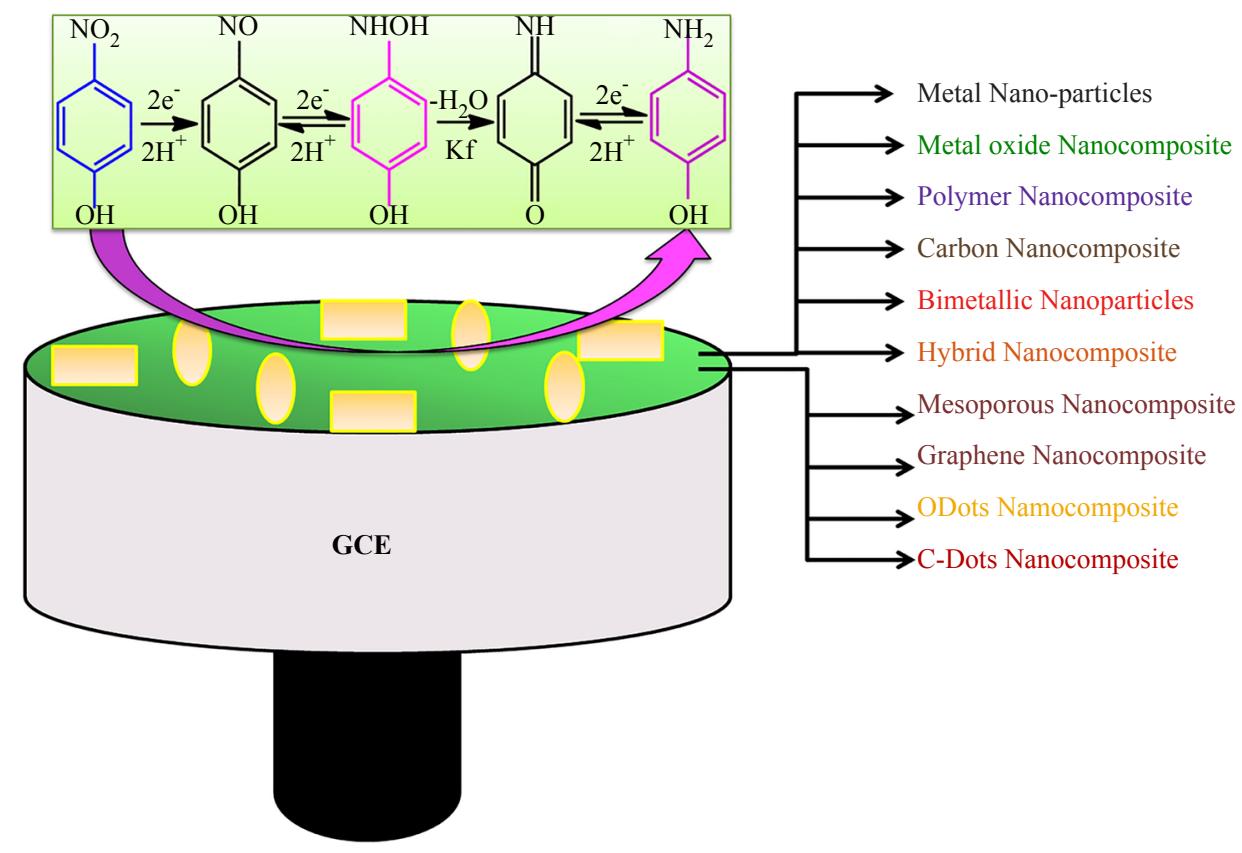

Figure 5. Different nanomaterials modified GCE for electrochemical detection of 4-NPh

Table 1. The different nanomaterials are classified for electrocatalytic reduction of 4-NPh

\begin{tabular}{ccccc}
\hline S.NO & Modified GCE & Linear range $(\mu \mathrm{M})$ & Detection limit $(\mu \mathrm{M})$ & References \\
\hline 1 & PDDA-G & $0.06-110$ & 0.02 & 88 \\
2 & Ag-rGO & $1-1100$ & 0.32 & 89 \\
3 & GO/TiO2/GCE & $0.02-80.57$ & 3.9 & 90 \\
4 & GCE-AuNPs-rGO & $0.05-2$ & 0.02 & 91 \\
5 & Green Ag-NPs/GCE & $0.09-82.5$ & 60 & 92 \\
6 & GCE/Ag-chitosan & $0.07-2.0$ & 70 & 93 \\
7 & Cu-curcumin/GCE & $0.1-030$ & 68.2 & 94 \\
8 & GCE/rGO & $50-800$ & 200 & 96 \\
9 & NMP-Graphene & $0.5-5.6$ & 0.15 & 97 \\
10 & GCE-rGO-CD-CS & $0.06-40$ & 16 & 98 \\
11 & ZnO-chitosan & $0.5-400$ & 0.23 & 99 \\
12 & GCE-Green AgNPs & $0.5-3000$ & $0.5-3000$ & 100 \\
13 & GCE-chitosan-BMIMBF-MWCNT & $0.3-20$ & 0.1 & 101 \\
14 & GCE-Au NPs & $10-1000$ & 8 & 102 \\
15 & GCE-PANi-GITN & $0.03-3$ & 0.0052 & \\
\hline
\end{tabular}

PDDA-G: poly (diallydimethylammonium chloride)-graphene; NPs: nanoparticles;

BIMIMBF: 1-butyl-3-methylimidazolium tetrafluoroborate;

MWCNT: multi-walled carbon nanotube;

rGO: reduced graphene oxide;

PANi-G-ITN-Integrated polyaniline with graphene oxide-iron tungsten nitride nanoflakes;

rGO-CD-CS Reduced graphene oxide-cyclodextrin-chitosan;

NMP-N-methylphenazoniummethyl sulfate. 


\section{Graphene materials for electrochemical sensors}

Graphene is a kind of carbon material with a unique structure when compared to other carbon materials. Graphene comprises a 2D dimensional sheet of $\mathrm{sp}^{2}$ hybridizede carbon atoms. The dense arrangement of carbon is in a honeycomb crystal lattice. This carbon sheet layers are bonded with weak Van der Waals Forces [103]. Graphene has unique electrical conductivity when compared to other carbon materials. GO is synthesized by numerous methods which include heat, chemical conversion and electrochemical methods as shown in Figure 6. GO facilitates fast electron transfer between the edge of oxygen and defects [104-106]. Consequently electrochemical sensors can be prepared with graphene-based materials [107-109]. Chemically modified rGO has exhibited better electrochemical sensing due to oxygen-containing functional groups. This is without difficulty modified with special functionalization which include modification with biological molecules and polymers [110-112]. 4-NPh is easily detectable using metal nanoparticles, metallic oxide nanoparticles, carbon nanocomposites and polymer nanocomposites with graphene as shown in Figure 7. This graphene nanocomposite has delivered a fast electrochemical sensor with unique analytes such nitrophenols, trinitrotoluene, picric acid (PA), nitrobenzene, $\mathrm{H}_{2} \mathrm{O}_{2}$ and dihydroxy benzene isomers.

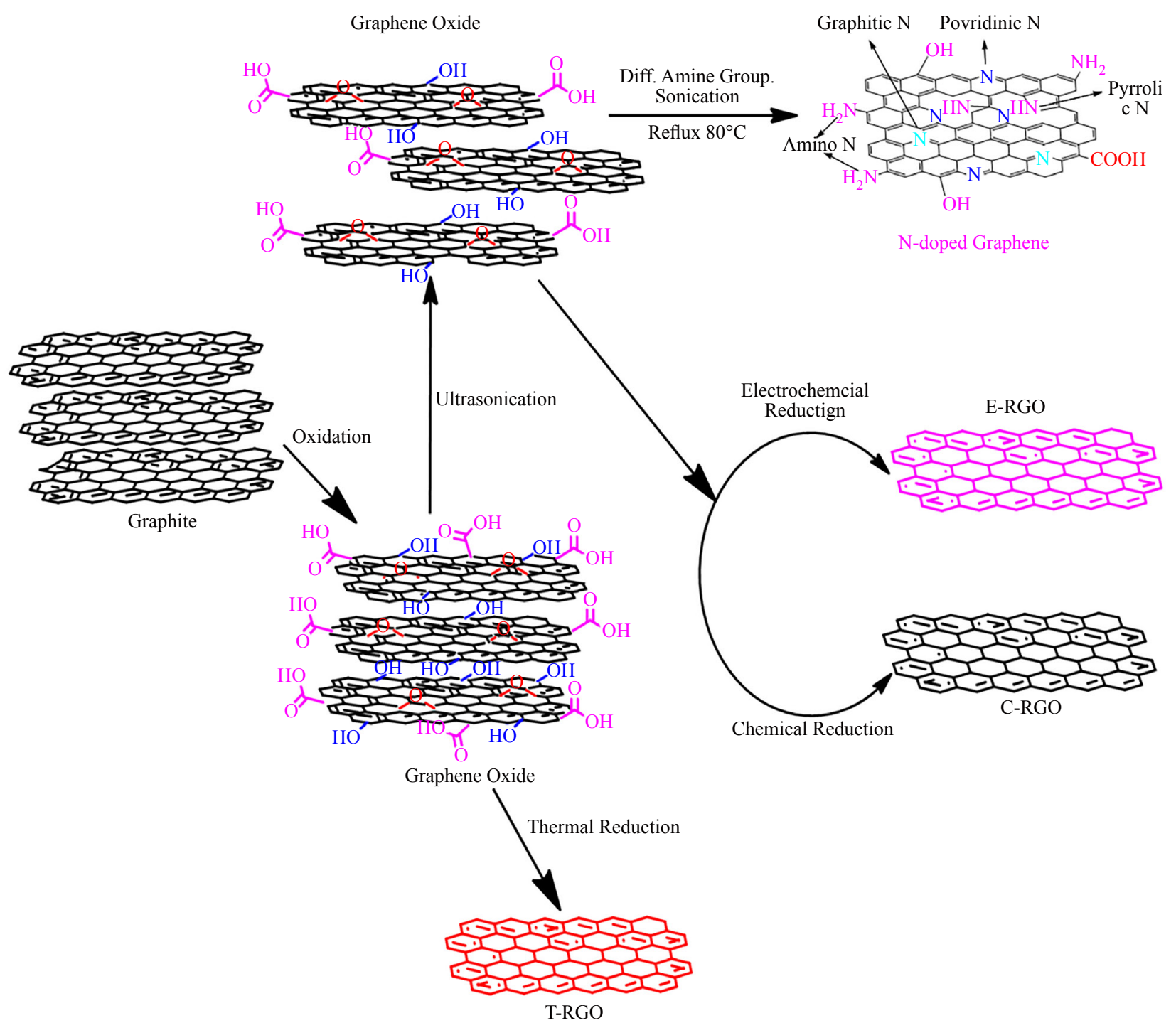

Figure 6. Different ways of synthesis of GO, graphite oxide with thermally, chemically and electrochemically 

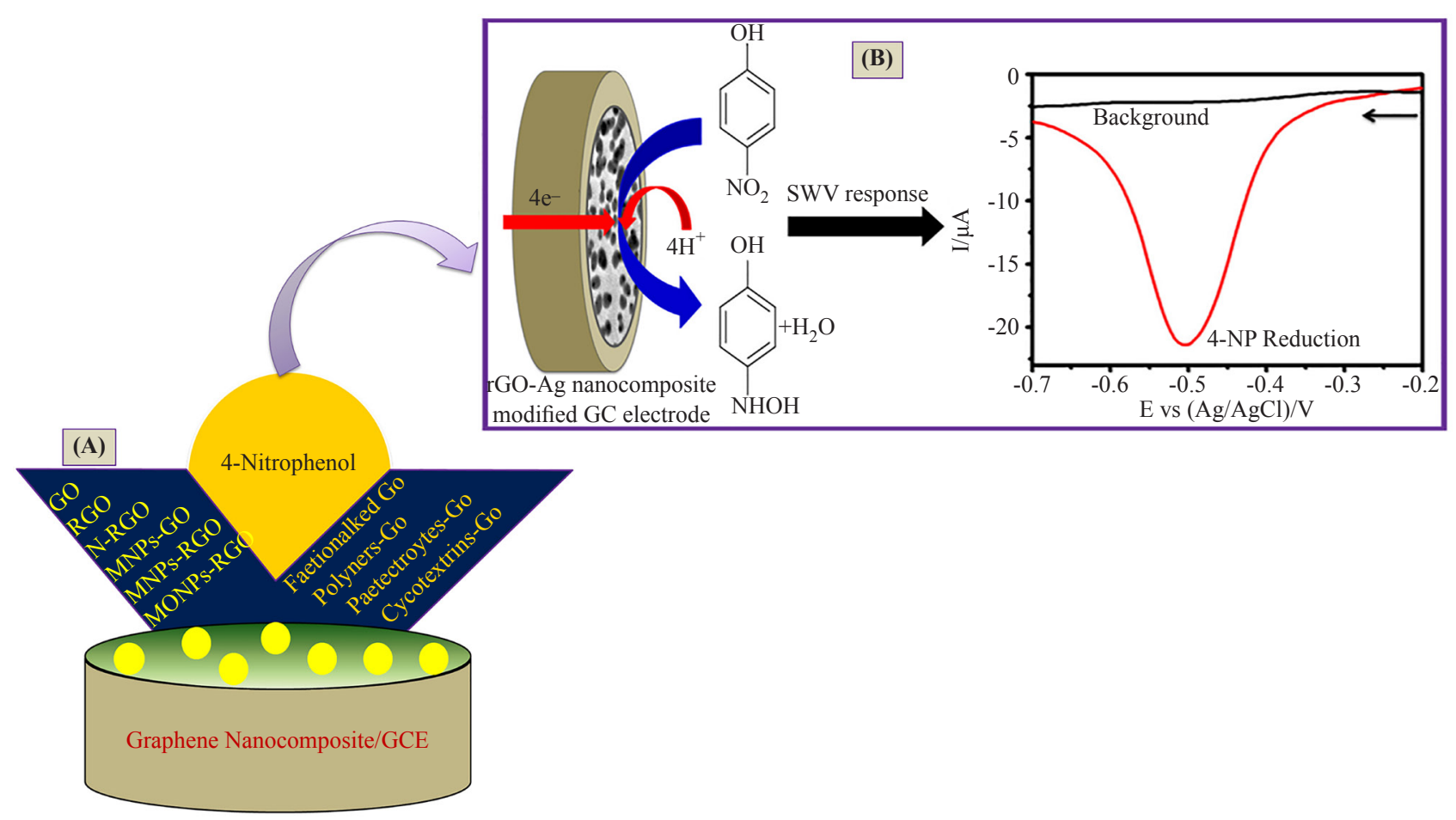

Figure 7. (A) Different graphene and graphene nanocomposites modified GCE for detection of 4-NPh. (B) Schematic representation of the electrocatalytic reduction of 4-NPh at rGO-Ag nanocomposite-modified GCE. (B) Figure only reprinted with permission from ref. 83, Copyrights (2014) Elsevier Publications

\section{Electrochemical sensors of 4-NPh by using graphene materials nanocomposite}

Metal nanoparticles, Metallic oxide nanoparticles, Polymers nanocomposites and Carbon nanocomposites are in high demand for the electrochemical detection of 4-NPh. These show superior accuracy with electrocatalytic sensing and selectivity with different analytes. GO has a 2D lattice shape and has significantly developed as an electrocatalyst and electrochemical sensor. It has a better electron transfer abilities due to the large number of functional groups such as $\mathrm{COOH}, \mathrm{OH}$ and the epoxy group. The functional groups of $\mathrm{GO}$ can improve fast electron transfer between the electrode and analyte. This also involves heterogeneous electron transfer between the GO modified electrode and analytes. $\mathrm{GO}$ is also capable of faster electrochemical sensing when compared to other materials. GO has shown good electric conductivity, stability, sensitivity and kinetic electron transfer rate due to nano graphite impurities in carbon nanotubes [113]. Li, et al. fabricated a GO modified GCE (GO/GCE) and it showed good catalytic capability to reduce 4-NPh. The modified $\mathrm{GO} / \mathrm{GCE}$ has a strong adsorptive capability and clear electronic characteristics due to hydrogen bonding and hydrophobic forces between GO and 4-NPh [114-115]. Since 4-NPh has an aromatic group, it can also engage in $\pi-\pi$ stacking interactions with GO. There may also be electrostatic interactions between GO and 4-NPh where the N atom in 4-NPh can become positively charged. These properties have resulted in high electrochemical detection of 4-NP on GO. In contrast to different NPh chemical sensors based on chemically rGO substances, studies on the electrochemical detection of $4 \mathrm{NPh}$ do not show better stability and reproducibility, but rather result in the selective reduction of 4-NPh once this is electrochemically detected. The reduction peak current concentration range is from 0.1 to $120 \mu \mathrm{M}$ for 4-NP and its limit of detection (LOD) is $0.02 \mu \mathrm{M}$.

Electrochemical procedures have reported the electrodeposition of GO on GCE surface and formation of electrochemical reduction graphene oxide (ERGO) films is exhibited as crumpled, wrinkled and flake-like shapes [8790]. In recent years, researchers have improved the stability and sensitivity of modified ERGO on GCE films, which can be used to enhance electrochemical sensors [116-121]. In ERGO film formation a few defects are found such thickness management, inability to separate the films and analyte and the analytes are mostly present on the surface of ERGO films [122]. Hence, an easy route for synthesizing ERGO films on GCE has been developed and these can 
be directly attached on GCE from GO dispersion with single step. Wu et al. reported the simple preparation of ERGO nanocomposite films by using a co-electrodeposited method [123]. Further, ERGO modified electrodes have been designed with single step electrodeposition methods. This system is used to assemble the ERGO films on GCE and result in good rapid electron transfer for the electrochemical sensor. Since this electrodeposition technique has been confirmed to be very significant it has been applied for ERGO based nanocomposite sensors for the electrochemical detection of analytes.

Rao et al. used electrochemically rGO films on GCE (ERGO/GCE) for the detection of 4-NPh [124]. This kind of modified electrode was used for the electrocatalytic reduction of 4-NPh because of edge plane defect of ERGO for the electrocatalytic reduction of 4-NPh. Therefore, ERGO/GCE are promising for the electrochemical sensing of 4-NPh. ERGO/GCE films were confirmed as electroactive substrates for sensing analytes. ERGO can be without difficulties shaped on the film on GCE with a one-step electrochemical approach and electrocatalytic activity through 4-NPh reduction and oxidation due to amino and hydroxyl groups. Chen et al. suggested that the modified ERGO/GCE film is formed by the electrodeposition technique. This technique has facilitated the use of ERGO films from GO due to fast electron transfer and the green approach [125]. Here, the graphene films are synthesized on GCE directly from GO with single steps of the electrodeposition method [126]. This modified ERGO electrode delivered a terrible fouling effect, desirable balance, sensitivity and higher electrochemical sensing of 4-NPh.

Oliveira et al employed the novel nanocomposite of N-methylphenazonium methyl sulfate (NMP) adsorbed on graphene for the electrocatalytic reduction of 4-NPh. This NMP/RGO is fabricated on a GCE electrode to facilitate the powerful electrochemical detection of 4-NPh. N-methylphenazonium methyl sulfate acts as an electron transfer mediator between RGO and GCE and has high stability, and results in the fast electrochemical redox reaction in 4-NPh determination [127-128]. This nanocomposite exhibits a non-covalent linkage between the RGO and NMP to enhance the electrocatalytic reduction of 4-NPh. NMP/RGO/GCE electrode detects 4-NPh at a concentration of up to $0.3 \mathrm{nM}$ through DPV and $0.15 \mathrm{nM}$ with the aid of Amperometry, $(\mathrm{S} / \mathrm{N}=3)$. NMP/GO/GCE electrode is viable, stable, sensitive and results in rapid determination of 4-NPh.

\section{Electrochemical sensor of 4-NPh by N-doped RGO nanocomposite}

Enhanced electrical conductivity, electrocatalysis and electrochemical sensors are needed with modified GO containing heteroatoms such as S, N, P and B [129-130]. Amongst them, a N-doped graphene oxide structure may be involved in extraordinary applications [131-132]. N-doped graphene oxide supplies a quick electron transfer rate and reduces the band gap for electrochemical applications [133]. The nitrogen atom is smoothly doped with different chemical materials because of its atomic size and lone pair electron and it is able to without difficulty be doped with carbon materials consisting of carbon atoms with strong bonds [134]. The lone pair of electrons on the nitrogen atom is doped on rGO carbon materials that have aromatic moieties, increase electric conductivity and change the band gap of rGO [135-136]. GO has not exhibited any activity improvement, so N-doped graphene oxide can be utilized for the numerous applications of electrocatalysis and electrochemical sensors [137]. N-doped graphene oxide can be prepared by different methods including nitrogen plasma process [138], arc-discharge [139], segregation growth [140], chemical vapour deposition [141-142], thermal annealing [143-144], hydrothermal techniques [145-146] and solvothermal methods [147].

However, modification has been used on GCE and has more suitable electrochemical sensors and electrocatalysis [148]. The connectivity of the N-doped graphene oxide consisting of graphitic N, pyridinic-N and pyrrolic $\mathrm{N}$ have specific properties which increase the surface area and enhance the electrocatalytic activity with the thermal remedy of melamine and 2-methyl imidazole [149] as shown in Figure 8. Exceptional kinds of N-doped graphene oxide materials have shown the tremendous electrochemical behavior which is closer to the 4-NPh sensor. Zhang and coworkers prepared the N-doped graphene oxide with urea combination by using solvothermal methods [150]. Giribabu and coworkers prepared N-doped graphene oxide by using the solvothermal method of GO and sodium diethyldithiocarbamate mixture [151]. Dadkhah and coworker synthesized N-doped graphene oxide which was prepared by the solvothermal method of GO and 3-aminopropyltriethoxysilane (APTES). This improvement of N-GO has resulted in crucial issues together with structural modifications. Hydrogen bonding is formed the $\mathrm{N}$ atom and GO and $\pi-\pi$ bond interplay of N-GO and analytes [152-153]. N-GO modified GCE is implemented for electrochemical application 
4-NPh.

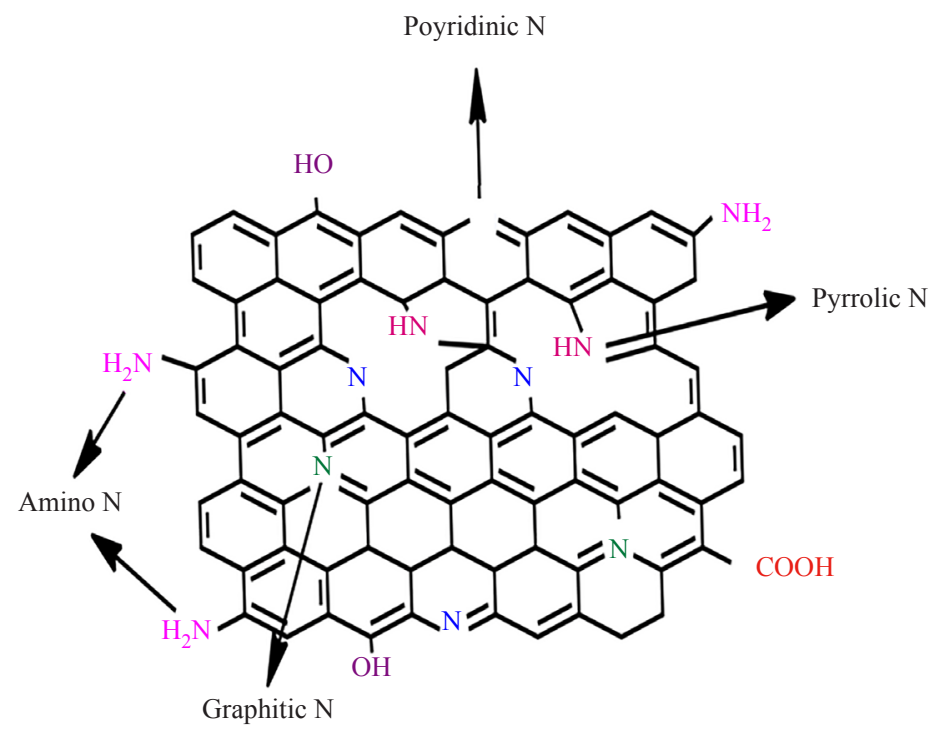

Figure 8. Synthesis process of nitrogen-doped graphene and illustration of types nitrogen configurations in N-doped graphene. Green, blue and red colour represents graphitic $\mathrm{N}$, pyridinic $\mathrm{N}$ and pyrrolic $\mathrm{N}$ respectively

\section{Electrochemical detection of 4-NPh using functionalized on GO nano- composite}

GO is an attractive material and its properties are utilized in electrochemical applications. The GO is without difficulty agglomerated by chemical conversion techniques and it easily gets graphitized from GO due to van der walls forces and $\pi-\pi$ stacking interplay [154]. These substances have controlled utility, so issues are involved in opposition to graphitization and agglomeration. The modification of GO substances are wanted with covalent and non-covalent bonds by using functionalization techniques. In which non-covalent strategies onto GO are special properties consisting of the blockage of the agglomeration of the layer of GO with the hydrophilic or hydrophobic organization, increased solubility and increase electrochemical application examine than covalent technique [155-156]. Therefore, polymers, non-covalent- polyelectrolyte and macromolecules are used to alter GO [157]. Peng et al. posted the research on a modified electrode via the usage of polyelectrolyte (poly (diallyldimethylammonium chloride) (PDDA))-functionalized GO for the electrochemical detection of 4-NPh [158]. Poly (diallyldimethylammonium chloride), PDDA is engaging in an ionic polymer and it can be bonded to GO sheets [159-162]. Therefore, PDDA is functionalized with GO to create a positive charge and so that it can without difficulty attract negative materials for different applications [163-164]. This electrostatic attraction of materials has reduced the electrochemical catalyst's activity and resulted in low detection of $0.02 \mu \mathrm{M}$ of 4-NPh [165-166].

Bharath et al. proposed the synthesis of edge-carboxylated GO from graphite powder and magnetite-hydroxyapatite (m-HAp) which is coated on nicely defined GO through the use of the hydrothermal method. m-HAp onto GO nanocomposite offers an effective electrochemical detection of phenolic natural pollution for environmental protection [167]. m-HAp-GO nanocomposite confirmed the adsorbing behavior and it can't be reused and recycled after treatment. The technique is wanted severely to solve the problems. So the guided side-carboxylated GO sheet is utilized by ball mill techniques. m-HAp nanocomposites covered on GO is conducted by way of hydrothermal approaches. The resulting m-HAp/ECGO is modified on GCE for the electrocatalytic reduction of 4-NPh [168]. The modified m-HAp/ $\mathrm{ECGO} / \mathrm{GCE}$ sensor offerssuitable sensitivity, selectivity and the low detection limits which is $0.27 \mu \mathrm{M}$. Arfin et al. produced graphene oxide-poly (ethyleneimine) dendrimer (GO-PEI) functionalized modified GCE electrode through a drop-cast approach [169]. The modified GO-PEI/GCE shows better electrochemical sensing of o-NPh and good 
redox properties is observed. GO-PEI/GCE offers the concentration of o-NPh from 5-155 $\mu \mathrm{M}$ and limit of detection is $0.10 \mu \mathrm{M}(\mathrm{S} / \mathrm{N}=3)$. GO-chitosan nanocomposite on the GCE is fabricated for the electrochemical sensor of 4-APh by using using the voltammetry approach [170]. GO with polyaniline nanocomposite (GO-PANI) was prepared and applied in the electrochemical determination of 4-APh. GO-PANI nanocomposite was fabricated on GCE to faciliate the electrocatalytic sensing of 4-APh through the cyclicvoltammetry approach. GO-PANI/GCE electrode has performed a higher electrochemical reaction in 4-APh with low detection limit, suitable sensitivity, better stability and simultaneous determination of 4-APh. This GO-PANI/GCE electrode is used as sensor and biosensor based on the method [171]. GOPANI nanocomposite GCE film is able to perform an effective electrocatalytic reduction of 4-APh and has a detection limit of $6.5 \times 10^{-8} \mathrm{M}$.

\subsection{Electrochemical sensor for NPh by using GO-MIP nanocomposite}

Liu, et al proposed the electrochemical application of 2, 4-DNPh with the molecular imprinted polymer (MIP) with GO nanocomposite modified GCE electrode. 2, 4-DNPh is used as a template to prepare MIP [172]. MIP-GO has an extraordinary surface area, great selectivity and shows better electrocatalytic determination of 2, 4-DNPh. GO-MIP/ GCE electrode has exhibited a low detection limit is $0.4 \mu \mathrm{M}(\mathrm{S} / \mathrm{N}=3)$ with DPV and GO-MIP/GCE resulted in the good sensitivity.

\subsection{Electrochemical sensor for 4-NPh by using GO-chitosan nanocomposite}

Deng et al advanced a newly modified electrode based on the acetylene black paste electrode graphene-chitosan composite film (GO-chit/ABPE) and it is able to electrochemically determine 2-NPh and 4-NPh simultaneously [173]. This resulted in detection limits of $200 \mathrm{nM}$ for 2-NPh and $80 \mathrm{nM}$ for 4-NPh, respectively. GO-Chit/ABPE electrode was successfully used for the electrocatalytic determination of 2-NPh and 4-NPh. The fabricated GO-Chit/ABPE electrode gave desirable stability, sensitivity and reproducibility and higher electrochemical detection of o-NPh and p-NPh. Tang et al introduced the graphene-chitosan composite film modified GCE (GO-Chit/GCE) become prepared for the simultaneous detection of $\mathrm{p}-\mathrm{NPh}$ and o-NPh. GO-CS/GCE confirmed better electrocatalytic interest for the reduction of $\mathrm{p}-\mathrm{NPh}$ and o-NPh. The detection limit $(\mathrm{S} / \mathrm{N}=3)$ of $0.09 \mu \mathrm{M}$ at GO-CS/GCE for o-NPh and detection limit of $0.1 \mu \mathrm{M}$. GO-CS was validated as a promising sensor for the simultaneous detection of NPhs isomers [174].

Yin et al reported that a graphene-chitosan composite is immediately coated on GCE electrode and it is capable of using the modified electrode for electrocatalytic reduction of 4-APh. GO-Chitosan nanocomposite has unique properties like excessive surface area easily made film shapes of chitosan polymers, good electrical conductivity and best electrocatalytic reduction of 4-APh. GO-chitosan has exhibited the efficient electrochemical utility of 4-APh with detection limit is $0.057 \mu \mathrm{M}(\mathrm{S} / \mathrm{N}=3)$ [175]. Fana et al proved that a graphene oxide polyaniline (GO-PANI) nanocomposite was used for an electrochemical application of 4-APh. GO-PANI nanocomposite is prepared through an in situ polymerization approach and this nanocomposite film is coated on GCE for the electrochemical determination of 4-APh with the cyclicvoltammetry method. This GO-PANI nanocomposite sensor exhibited a low detection limit $6.5 \times$ $10^{-8} \mathrm{M}$, excessive sensitivity and better stability for the electrochemical detection of 4-APh [176].

\subsection{Electrochemical sensor for 4-NPhs by using poly(sulfosalicylic acid)/GO}

Zheng et al proposed a new developed rGO-poly (sulfosalicylic acid (PSA) nanocomposite which was synthesized by a single step of the electrochemical approach. PSA/rGO nanocomposite was successfully fabricated on GCE for the electrochemical determination of acetaminophen. PSA/rGO/GCE electrode exhibited an extraordinary electrochemical detection of limit is of $0.041 \mu \mathrm{m}(\mathrm{S} / \mathrm{N}=3)$, high reproducibility, high stability and anti-interference capacity. The PSA/ $\mathrm{rGO} / \mathrm{GCE}$ electrode suggests a fantastic electrochemical behavior of acetaminophen with a synergistic effect between the PSA and rGO film to increase the electrochemical detection of acetaaminophen [177]. 


\section{Electrochemical sensor of 4-NPh by using MNPs with GO nanocomposite}

Metals and Metallic oxide nanocomposites modified GCE are extensively used as electrochemical sensors. These nanomaterials are coated on GO to show the best electrocatalytic behavior, great conductivity, selectivity and electrochemical sensing after modification with GCE. These nanomaterials give the better reduction peak current in 4-NPh detection and low interference effects.

Yang reports the synthesis of a GO/AgNPs nanocomposite via a hydrothermal method and AgNPs were uniformly coated on the GO sheet. AgNps/GO nanocomposite was coated on GCE and it can be tested for the super electrochemical sensingof 4-NPh with the low detection limit of $0.114 \mu \mathrm{M}$. This nanocomposite exhibited the following characteristics such as stability, anti-interference and sensitivity [178]. Mohamed Noor et al. reported the preparation of a reduced graphene oxide-silver (rGO-AgNPs) nanocomposite by using a microwave method and the rGOAgNPs nanocomposite was modified on a GCE to provide rGO-AgNPs/GCE. This rGO-AgNPs/GCE was used for the electrocatalytic reduction of $4-\mathrm{NPh}$ and additionally exhibited the limit of detection $0.32 \mu \mathrm{M}$. These observations confirmed that the rGO-AgNPs nanocomposite exhibited desirable selectivity toward the detection of 4-NPh even in the presence of different interfering molecules [179].

Ikhsan et al conducted a simple synthesis of a silver nanoparticle-coated GO AgNPs-rGO nanocomposite with Tollen's reagent at different time intervals. AgNPs-rGO nanocomposite modifies GCE to give AgNPs-rGO/GCE. This modified AgNPs-rGO/GCE was able to engage in the electrochemical detection of 4-NPh bythe use of SWV with a detection limit of $1.2 \mathrm{nM}$ [180]. Karuppiah et al verified that the green method of preparation of silver nanoparticles with justicia Glauca leaf extract as a reducing agent. In addition, the silver nanoparticles were dispersed on GO to provide the AgNPs-rGO nanocomposite and this AgNPs-rGO nanocomposite was modified on the GCE to apply the electrochemical software for the detection nitrobenzene [181]. AgNPs-rGO/GCE showed a low limit of detection of 0.261 $\mu \mathrm{M}$ and showed the best selectivity and anti-interference.

Tang et al organized an unconventional sensor of AuNPs/rGO nanocomposite and it can be made on the GCE film electrode for the electrochemical detection of 4-NPh. The AuNPs/rGO/GCE sensor is prepared by using the electrochemical deposition cyclicvoltammetry technique. The AuNPs/rGO/GCE sensor exhibited the good electron change between the electrolyte and electrode and effortlessly improved the electrocatalytic response of 4-NPh. This sensor showed a low detection of 4-NPh with $0.01 \mu \mathrm{M}$ and $0.02 \mu \mathrm{M}$ by using Difference Pulse Voltammetry and SWV, respectively. AuNPs/rGO/GCE showed anti-interference activity, reliability and effective electrochemical of detection of 4-NPh [182]. Jiao et al. verified the synthesis of gold nanoparticles coated with GO nanocomposite (AuNPs/rGO) film by the electrochemical technique. AuNPs/rGO nanocomposite performed as a sensor with the aid of GCE and this AuNPs/rGO/GCE is implemented for the electrochemical dedication of 4-NPh with electrochemistry techniques. AuNPs wereimmobilized on rGO materials to improve the peak current and shifted the reduction potential of 4-NPh with the cyclicvoltammetry approach. It was well determined that the AuNPs/rGO/GCE films showed a good electrochemical signal for 4-NPh. AuNPs/rGO/GCE showed a low detection limit of $1.0 \times 10^{-8} \mathrm{M}$, excessive sensivity, repeatibilty and stability in 4-NPh detection [183]. Wenbei et al showed the unconventional technique of modifying GO with gold nanoparticles (AuNPs/GO), wherein AuNPs is loaded in a very small amount of $10 \%$ and AuNPs is dispersed on the grpahene oxide sheet without any aggregation. AuNPs-GO nanocomposite is fabricated on GCE to present AuNPs/GO/ GCE and it can be capable of detecting the 4-NPh by means of the Amperometric method with low detection of 0.47 $\mu \mathrm{M}$. Au-GO/GCE can be effectively used as a powerful sensor material for the detection of 4-NPh [184-185].

Ezhil Vilian confirmed the environmentally friendly sensor of Pd-GA/rGO nanocomposite which is prepared with GA as a reducing agent. Pd-GA/rGO nanocomposite resulted in higher electrocatalytic and catalytic reduction of nitrophenol [186]. The catalytic abilities of Pd-GA/rGO nanocomposite are improved for GO to offer the good electrostatic interaction of rGO and 4-NPh. PdNPs exhibited more surface with GA-rGO and it is able to effortlessly unfold out on the GA-rGO surface to cause rapid electron transfer and electrocatalytic reduction of 4-NPh. Pd-GA/rGO nanocomposite modified GCE electrode gave a lower overpotential, excessive sensitivity and limit of detection is 9 fm (S/ $\mathrm{N}=3$ ) with SWV. Pd-GA-rGO nanocomposite suggests higher catalytic activity with 4-NPh and the synergistic effect produced between the rGO and PdNPs to enhance the electrocatalytic and catalytic of 4-NPh as proven in Figure 9. 
(A)

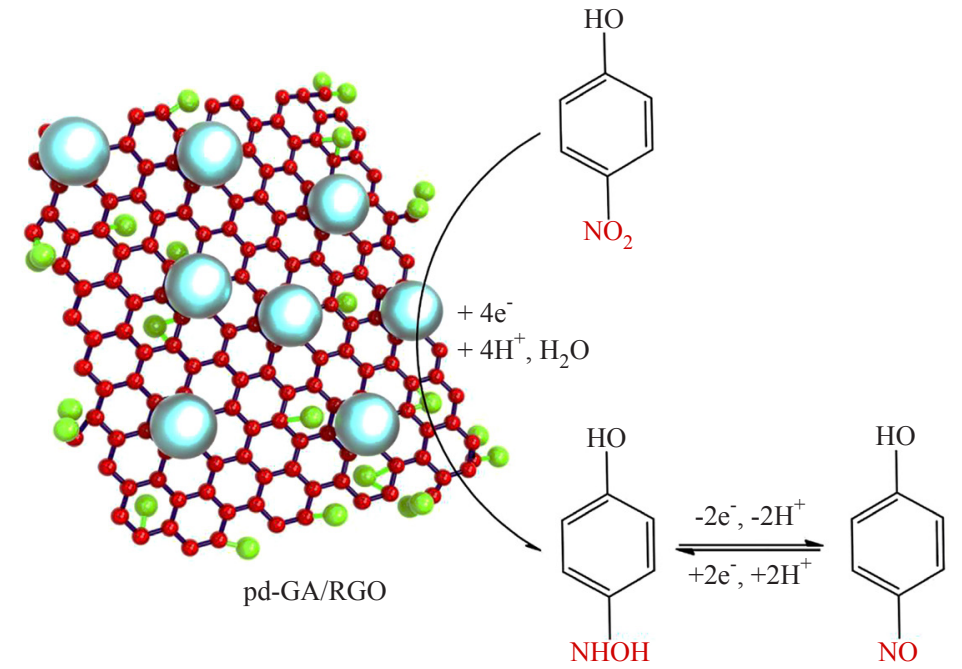

(B)

(a)

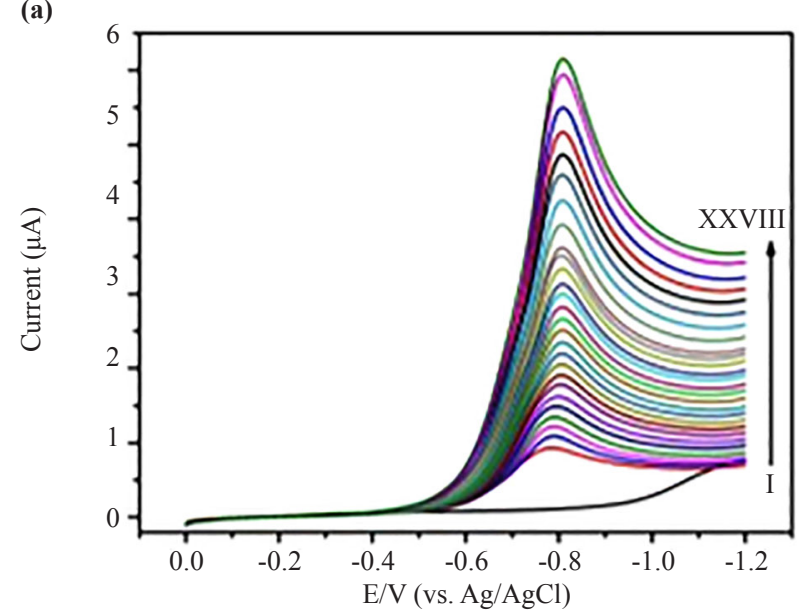

(c)

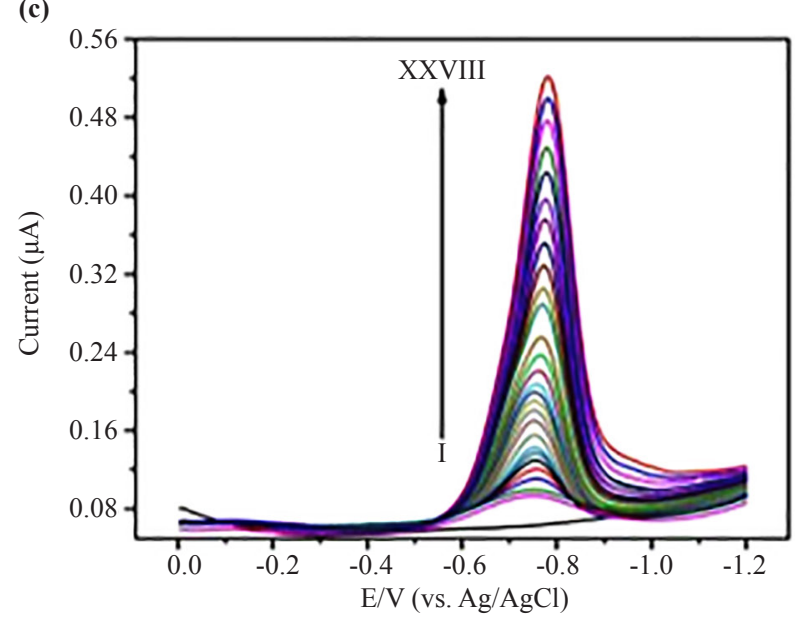

(b)

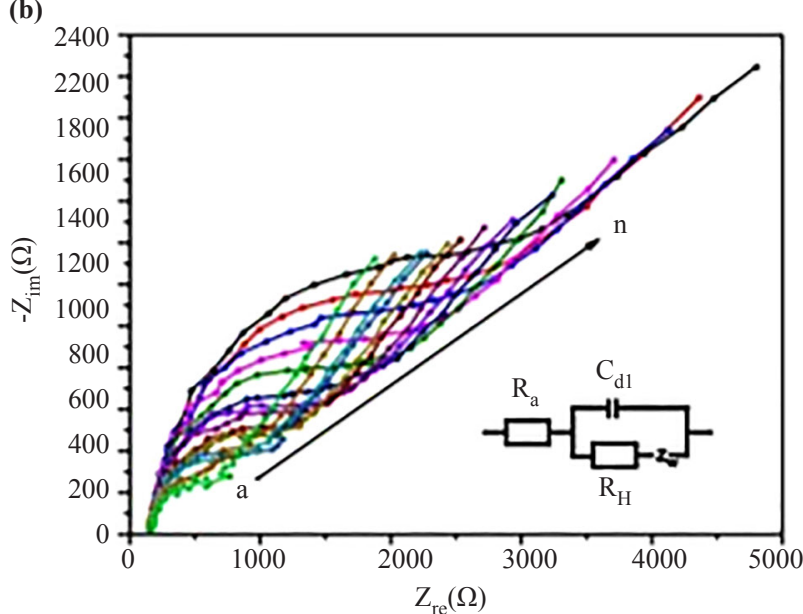

(d)

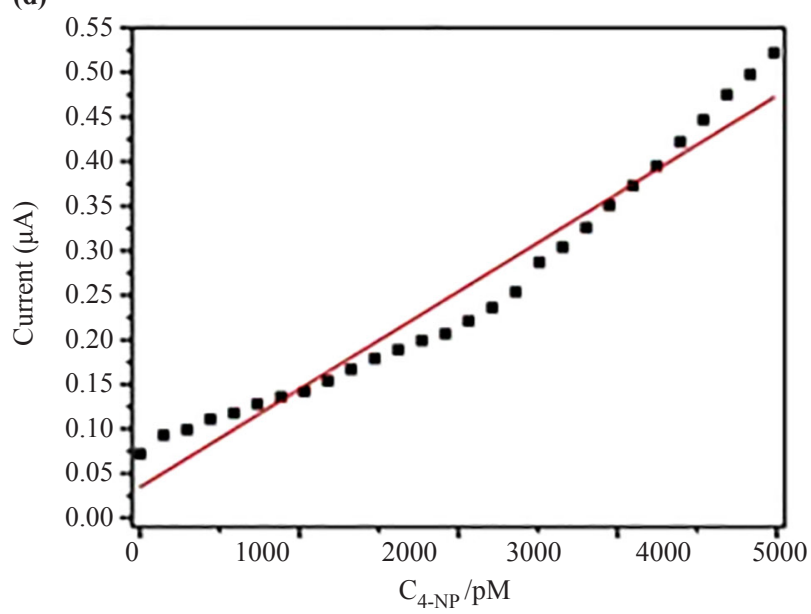

Figure 9. (A) Schematic illustration of 4-NP electrochemical reduction at Pd-GA/RGO/GCE. (B) (a-d) LSV curves of 4-NP on Pd-GA/RGO in 0.05 M PBS with various concentrations (from curve I to xxviii $=0-400 \mathrm{pM}$ ). (b) EIS of the Pd-GA/RGO with various 4-NP concentrations (from curve a' to $\mathrm{n}=(0-300 \mathrm{pM})$ in PBS $(\mathrm{pH}=7)$ containing $5 \mathrm{mM} \mathrm{Fe}(\mathrm{CN})_{6}^{3-4-}$ with $0.1 \mathrm{M} \mathrm{KCl}$. (c) SWV curves of increasing different $(0-80 \mathrm{pM})$ concentrations of 4-NP obtained with a Pd-GA/RGO sensor in a pH 7.0 solution. (d) Consequent calibration plot for cathodic peak currents and 4-NP concentrations. Conditions: 0.05 M PBS (pH 7.0). Reprinted with permission from ref. 186, copyrights (2014) Elsevier Publications. 


\section{Electrochemical sensor of 4-NPh by using MONPs with GO nanocomposite}

(A)
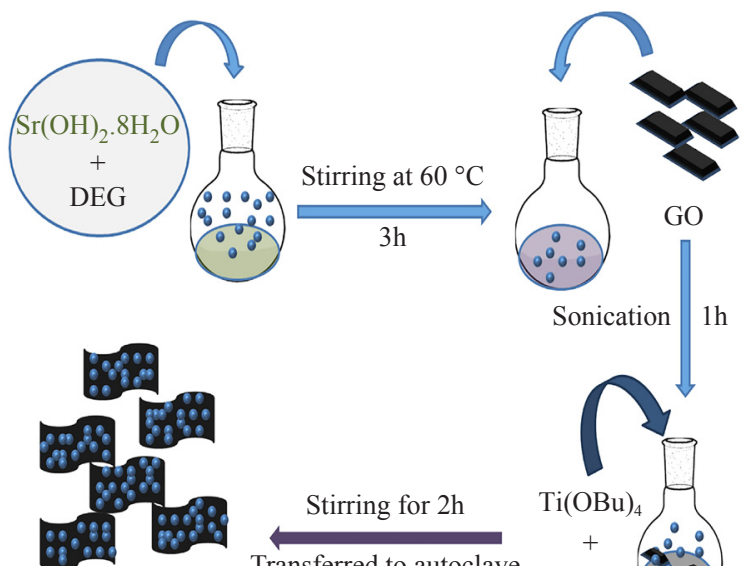

$\mathrm{rGO} / \mathrm{SrTiO}_{3}$ nano composite

\section{Stirring for $2 \mathrm{~h}$}

Transferred to autoclave

at $180^{\circ} \mathrm{C}$ for $24 \mathrm{~h} \quad \mathrm{TBAH}$

(B)

(a)

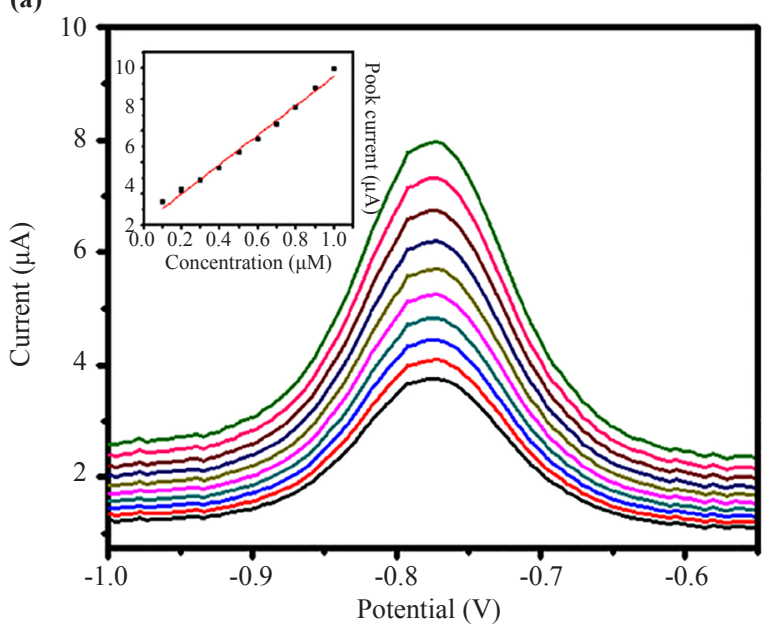

(c)

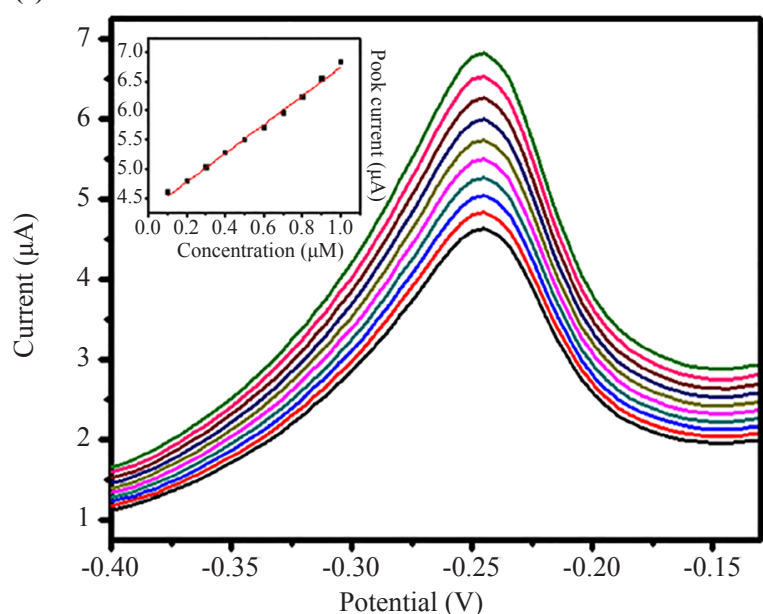

(b)

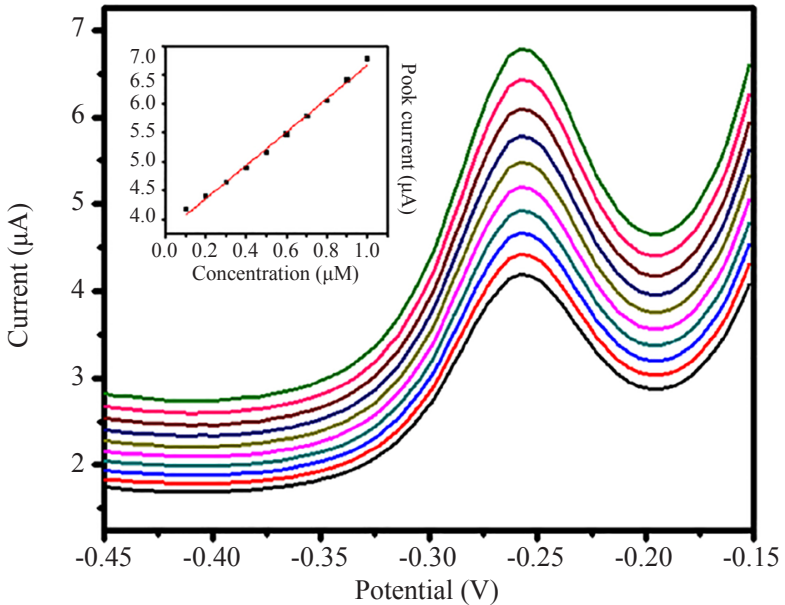

(d)

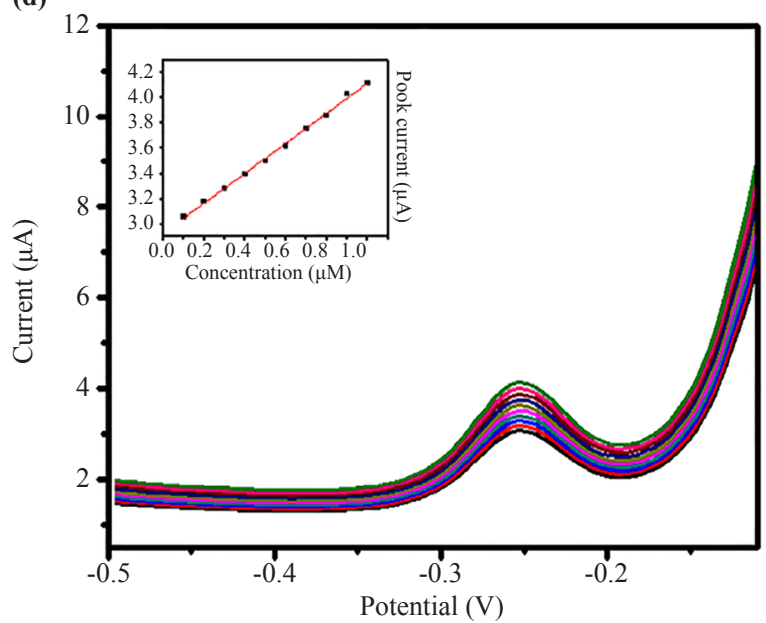

Figure 10. (A) Schematic representations for in-situ grown $\mathrm{rGO} / \mathrm{SrTiO}_{3}$. B(a-d) Differential pulse voltammograms of MGCE (a) for p-NP, (b) for 2,4DNP, (c) for 2,4-DNT and (d) for TNP at different concentration (0.1-1 mM) in PBS (pH 7.0) with a scan potential of $100 \mathrm{mV} / \mathrm{s}$. The inset showing the calibration plots of peak current versus concentration. Reprinted with permission from ref. 190, copyrights (2014) Elsevier publications 
$\mathrm{MnO}_{2}$-reduced $\mathrm{GO}$ nanocomposite is utilized as a modified electrode on GCE for the electrochemical application of 4-NPh. Right here, $\mathrm{MnO}_{2}$ nanoparticles is loaded on reducing $\mathrm{GO}$ by means of the electrodeposition method. $\mathrm{MnO}_{2}$ $\mathrm{rGO} / \mathrm{GCE}$ has remarkably showed the best electrocatalytic reduction of 4-NPh with the limit of detection of $10 \mathrm{nM}$. This sensor nanocomposite exhibited better stability, high selectivity, speed of electron transfer and reproducibility in 4-NPh detection [187]. Haldorai et al suggested the alpha- $\mathrm{MnO}_{2}$-Reduced $\mathrm{GO}$ nanocomposite can be prepared by using a residue free method. $\mathrm{MnO}_{2}$-Reuced $\mathrm{GO}$ nanocomposite is at once, bound without any binding agent within the electrocatalytic reduction of 4-NPh. This sensor displays a low detection limit of $0.017 \mu \mathrm{m}$ through $\mathrm{SWV}$. This $\mathrm{MnO}_{2}-$ $\mathrm{rGO} / \mathrm{GCE}$ electrode resulted in higher sensitivity, anti-interference capacity, and powerful electrocatalytic detection of 4-NPh [188].

Alam et al. showed that a reduced graphene oxide-Zinc oxide $(\mathrm{rGO} / \mathrm{ZnO})$ nanocomposite is prepared by a simple chemical reduction method with polyethylene glycol. The $\mathrm{rGO} / \mathrm{ZnO}$ nanocomposite is effectively performed onto GCE for electrochemical application of 2-NPh. This $\mathrm{r}-\mathrm{GO} / \mathrm{ZnO}$ nanocomposite is modified on GCE a thin layer of nanocomposite and increases the electrochemical sensing abilities, results in high sensitivity and a low detection limit of $0.27 \mathrm{nM}$. This $\mathrm{rGO} / \mathrm{ZnO}$ nanocomposite suggests a new approach for the improvement of better electrochemical sensing of 2-NPh [189].

The synthesis of $\mathrm{rGO} / \mathrm{SrTiO}_{3}$ nanocomposite is performed with the aid of a simple wet chemical approach with an in-situ technique. The $\mathrm{rGO} / \mathrm{SrTiO}_{3}$ nanocomposite is covered onto GCE with drop casting method. $\mathrm{rGO} / \mathrm{SrTiO}_{3}$ nanocomposite exhibited fast electron transfer among the active substances and analytes and development of electrode substances and electrolytes. It has been implemented for the electrochemical detection of nitro-substituted phenols such as 4-NPh, 2, 4-DNPh, 2, 4-dinitrotoluene (2, 4-DNT) and 2, 4, 6-Trinitrophenol (TNP) with low detection of (LOD) $110 \mathrm{nM}, 134 \mathrm{nM}, 128 \mathrm{nM}$ and $146 \mathrm{nM}$, respectively [190]. $\mathrm{rGO} / \mathrm{SrTiO}_{3}$ showed the excellent activity such as stability, reliability and anti-interference in the nitro aromatic pollutants results. The modified $\mathrm{rGO} / \mathrm{SrTiO}_{3} / \mathrm{GCE}$ exhibited a good electrochemical sensor of 4-NPh within the nitro-aromatic pollution as proven in Figure 10. Mahyar suggested brand new sensor of PtNPs-rGO nanocomposite on GCE for the electrochemical sensor of PA. PtNPs-rGO/GCE electrode is efficaciously applied the selective and sensitivity electrochemical sensor for PA with low detection limit of $1 \mu \mathrm{M}$ [191].

Electrochemical determination of nitrophenol derivative of acetaminophen has used the sensor of $\mathrm{Fe}_{3} \mathrm{O}_{4} \mathrm{NPs}_{\mathrm{s}}$ coated PDDA-GO nanocomposite. $\mathrm{Fe}_{3} \mathrm{O}_{4} \mathrm{NPs}$-PDDA-GO nanocomposite film is fabricated on GCE as a modified electrode for the sensitive detection acetaminophenol with cyclicvoltammetry. $\mathrm{Fe}_{3} \mathrm{O}_{4} \mathrm{NPs}-\mathrm{PDDA}-\mathrm{GO} / \mathrm{GCE}$ film sensor can be capable of determining the electrocatalytic activity of acetaminophenol with the aid of the usage of differential pulse voltammetry approach. The modified $\mathrm{Fe}_{3} \mathrm{O}_{4} \mathrm{NPs}-\mathrm{PDDA}-\mathrm{GO} / \mathrm{GCE}$ electrode resulted in significant detection of acetaminphenol with low detection of $3.7 \times 10^{-8} \mathrm{M}(\mathrm{S} / \mathrm{N}=3)$. The proposed electrochemical sensor also exhibited good reproducibility and stability and has been used to discover acetaminophen [192].

\section{Electrochemical detection of NPhs by using cyclodextrin based GO nano- composite}

Liu et al pronounced a $\beta$-cyclodextrin functionalized on reduced graphene oxide sheets ( $\beta$-CD-RGO) nanocomposite which is used as a sensor for 4-NPh derivatives including $\mathrm{p}-\mathrm{NPh}$, o-NPh and $\mathrm{m}-\mathrm{NPh}$ [175]. ( $\beta$-CD$\mathrm{RGO}$ ) nanocomposite is coated on GCE to supply the modified ( $\beta$-CD-RGO/GCE) electrode and is implemented in the electrocatalytic detection of NPhs. Here, RGO is a high surface region substance and easily accepts the host-guest group of cyclodextrin compounds. $\beta$-CD-RGO/GCE electrode has performed a higher electrocatalytic reduction in NPh and offers better redox peak current with the cyclicvoltammetric technique. $\beta$-CD-RGO/GCE was discovered for the electrochemical detection of NPhs to show good low detection limits of $0.05 \mu \mathrm{M}, 0.02 \mu \mathrm{M}$ and $0.1 \mu \mathrm{M}$ with p-NPh, $\mathrm{o}-\mathrm{NPh}$ and $\mathrm{m}-\mathrm{NPh}$, respectively. $\beta-\mathrm{CD}-\mathrm{RGO} / \mathrm{GCE}$ has brought appropriate sensitivity, true adsorptive, selectivity and anti-interference in the direction of NPhs. 
(A)
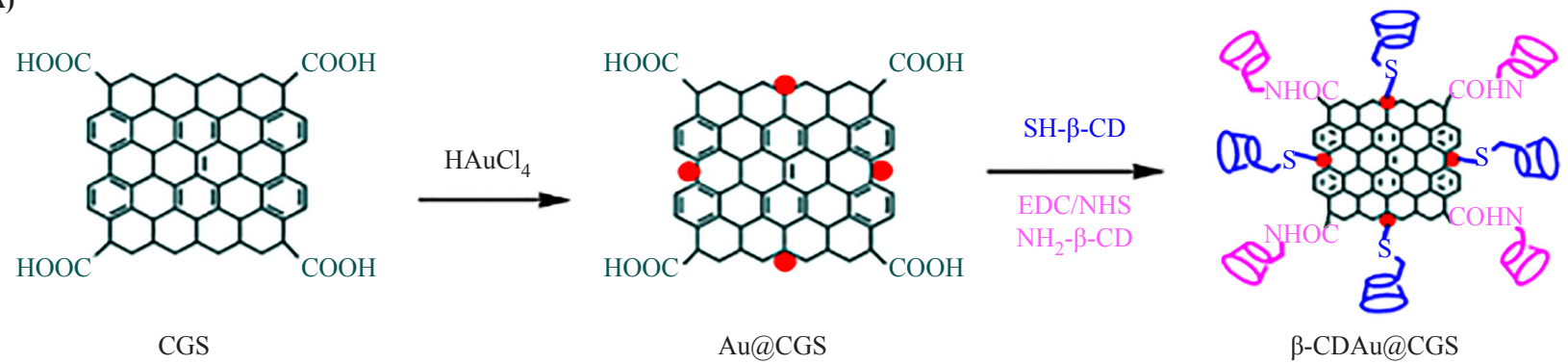

CGS

Au@CGS
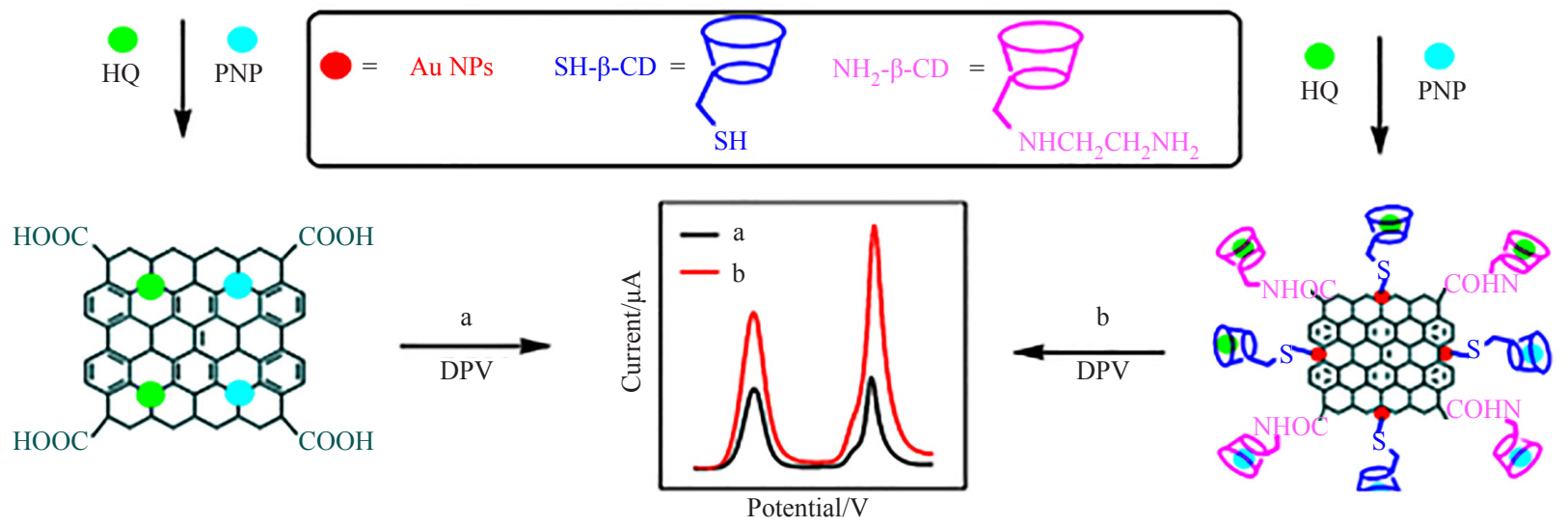

(B)<smiles>O=C1C=CC(=O)C(C=Cc2ccc(O)cc2)=C1</smiles>

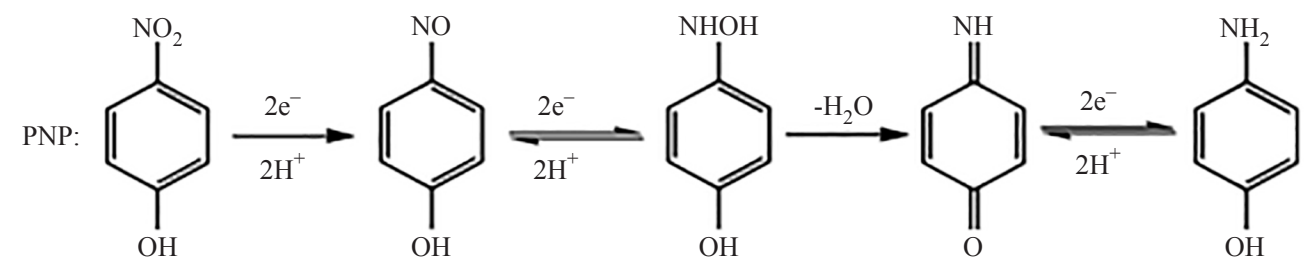

Figure 11. (A) $\beta$-CD-Au@CGS nanohybrids simultaneous sensing HQ and PNP by an electrochemical strategy. (B) The mechanisms of electron generation for HQ and PNP. Reprinted with permission from ref. 194, copyrights (2014) Elsevier publications

Li et al proposed a newly developed sensor of cyclodextrin functionalized with chitosan-reduced graphene oxide (CD-CS-RGO) for electrochemical utility of o-NPh and p-NPh by use of cyclicvoltammetry techniques [176]. CDCS-RGO nanocomposite is conducted on GCE to give CD-CS-RGO/GCE sensor in o-NPh and p-NPh simultaneous detection. This CD-CS-RGO hybrid nanocomposite has an existing synergetic effect among CS-RGO and CD and it is feasibly combined to enhance the electrocatalytic reduction of NPhs. CD-CS-RGO nanocomposite also exhibited the electrostatic interaction force among cyclodextrins (CDs) and chitosan. This attraction force has been improved the electrocatalytic determination of o-NPh and $\mathrm{p}-\mathrm{NPh}$ modified CD-CS-/GCE electrode. CD-CS-RGO/GCE is a satisfactory sensor in the determination of o-NPh and p-NPh with the limits of detection of $0.018 \mu \mathrm{M}(\mathrm{S} / \mathrm{N}=3)$ and 0.016 $\mu \mathrm{M}(\mathrm{S} / \mathrm{N}=3)$ respectively. $\mathrm{CD}-\mathrm{CS}-\mathrm{RGO} / \mathrm{GCE}$ electrode showed good stability, sensitivity, reproducibility and higher 
electrochemical detection of o-NPh and $\mathrm{p}-\mathrm{NPh}$.

Table 2. Electrochemical sensing of 4-NPh using GCE modified with various nanomaterials

\begin{tabular}{|c|c|c|c|c|c|c|c|}
\hline S.NO & Materials & Analytical technique & $\begin{array}{c}\text { Limit of } \\
\text { detection }(\mu \mathrm{M})\end{array}$ & Linear range $(\mu \mathrm{M})$ & $\begin{array}{c}\text { Correlation } \\
\text { coefficient }\left(\mathrm{R}^{2}\right)\end{array}$ & $\mathrm{pH}$ & Ref. \\
\hline 1 & GO & LSV & 0.02 & $0.1-120$ & 0.9975 & 4.8 & 46 \\
\hline 2 & RGO & DPV & 42 & $50-800$ & 0.9942 & 4.2 & 81 \\
\hline 3 & ${ }^{\mathrm{a}} \mathrm{GR} / \mathrm{MIP}$ & DPV & 0.005 & $0.01-100,200-1000$ & 0.9970 & 4.0 & 82 \\
\hline 4 & rGO-AgNPs & SWV & 0.0012 & $\begin{array}{c}0.01-0.1,0.1-1.0,1.0 \\
-11.0,11.0-101.0\end{array}$ & 0.998 & 7.2 & 83 \\
\hline 5 & AuNP/RGO & DPV & 0.01 & $0.05-2.0 \& 4.0-100$ & 0.9981 & 5.0 & 84 \\
\hline 6 & AuNP/RGO & SWV & 0.02 & $0.05-2.0$ & 0.9961 & 5.0 & 84 \\
\hline 7 & $\mathrm{MnO}_{2}-\mathrm{RGO}$ & LSV & 0.01 & $0.02-0.5 \& 2-180$ & $0.991 \& 0.995$ & 7.5 & 85 \\
\hline 8 & ${ }^{\mathrm{b}} \mathrm{Gr}-\mathrm{Chit} / \mathrm{ABPE}$ & LSV & 0.08 & $0.1-20 \& 20-80$ & 0.9976 & 1.0 & 87 \\
\hline 9 & ${ }^{c} \mathrm{EGS}$ & DPV & 0.04 & $0.2-20$ & 0.998 & 5.6 & 127 \\
\hline 10 & ${ }^{\mathrm{d}} \mathrm{ERGO}$ & DPV & 0.55 & $3.3-34.4$ & 0.9952 . & 7.0 & 128 \\
\hline 11 & ${ }^{\mathrm{e}} \mathrm{NMP} / \mathrm{Gr}$ & DPV & 0.0003 & $0.001-1.17$ & 0.998 & 5.0 & 132 \\
\hline 12 & $\mathrm{NMP} / \mathrm{Gr}$ & Amp & 0.15 & $0.50-5.60$ & 0.999 & 5.0 & 132 \\
\hline 13 & N-rGO & LSV & 0.007 & $0.020-0.5$ & 0.9953 & 6 & 155 \\
\hline 14 & ${ }^{\mathrm{f}} \mathrm{PCZ} / \mathrm{N}-\mathrm{GE}$ & $\mathrm{CV}$ & 0.062 & $0.8-20.0$ & 0.9971 & 4.6 & 156 \\
\hline 15 & ${ }^{g}$ PDDA-G & LSV & 0.02 & $0.06-110$ & 0.9964 & 7.0 & 162 \\
\hline 16 & ${ }^{\mathrm{h}}$ AuNPs/TWEEN/GO & Amp & 0.078 & $5-300$ & 0.999 & 7.4 & 169 \\
\hline 17 & im-HAp/ECG & DPV & 0.27 & $0.2-994$ & 0.9913 & 5.0 & 172 \\
\hline 18 & GR-CS & DPV & 0.09 & $0.1-140$ & 0.9891 & 4.5 & 179 \\
\hline 19 & RGO-Ag & Amp & 0.114 & $1-500$ & 0.9981 & 4.0 & 181 \\
\hline 20 & rGO-Ag & Amp & 0.32 & $1-1110$ & - & 6.0 & 182 \\
\hline 21 & rGO-Ag & SWV & 0.0012 & $0.1-1.0$ & 0.998 & 7.2 & 183 \\
\hline 22 & AuNP/RGO & DPV & 0.01 & $0.05-2.0$ & 0.9981 & 6.0 & 184 \\
\hline 23 & AuNP/RGO & SWV & 0.02 & $4.0-100$ & 0.9975 & 6.0 & 184 \\
\hline 24 & ${ }^{\mathrm{j}} \mathrm{ERG}-\mathrm{AuNP}$ & LSV & 0.01 & $0.036-90$ & 0.9983 & 4.0 & 185 \\
\hline 25 & ${ }^{\mathrm{k}} \mathrm{G}-\mathrm{Au} 10 \%$ & Amp & 0.47 & $0.47-1075$ & 0.9943 & Low $\mathrm{pH}$ & 186 \\
\hline 26 & 'Pd-GA/RGO & SWV & 0.0009 & $0.00002-0.0008$ & 0.9564 & 7.0 & 187 \\
\hline 27 & $\mathrm{MnO}_{2}-\mathrm{RGO}$ & LSV & 0.01 & $0.02-0.5 \& 2-180$ & $0.991 \& 0.995$ & 7.5 & 188 \\
\hline 28 & $\alpha \mathrm{MnO}_{2}-\mathrm{RGO}$ & SWV & 0.017 & $1-100$ & 0.9995 & 7.0 & 189 \\
\hline 29 & ${ }^{\mathrm{m}} \mathrm{rGO} / \mathrm{SrTiO}_{3}$ & DPV & 110 & $0.3-0.8$ & - & 7.0 & 190 \\
\hline 30 & ${ }^{\mathrm{n}} \mathrm{CD}-\mathrm{RGO}$ & DPV & 50 & $1000-10000$ & 0.997 & 4.0 & 191 \\
\hline 31 & RGO-CD-CS & DPV & 0.016 & $0.06-0.16 \& 5-40$ & 0.9870 & 5.0 & 193 \\
\hline 32 & $\beta-C D-A u @ C G S$ & DPV & 0.0038 & $0.01-5 \& 5-200$ & 0.998 & 6.0 & 194 \\
\hline
\end{tabular}

${ }^{\mathrm{a}}$ Molecularly imprinted graphene (GR/MIP);

${ }^{\mathrm{b}}$ Acetylene black paste electrode modified with a graphene-chitosan composite;

${ }^{\circ}$ Graphene nanosheets (GS);

${ }^{\mathrm{d}}$ Electrochemical reduction graphene oxide (ERGO);

${ }^{\mathrm{e}} \mathrm{N}$-Methylphenazonium methyl sulfate and graphene;

${ }^{\mathrm{f}}$ Polycarbazole (PCZ)/nitrogen-doped graphene (N-GE);

${ }^{g}$ Poly(diallyldimethylammonium chloride) (PDDA) functionalized graphene (PDDA-G) composite film;

${ }^{\text {h}}$ Polyoxyethylene sorbitol anhydride monolaurate (TWEEN 20) graphene oxide;

${ }^{\mathrm{i}}$ Magnetite-hydroxyapatite (m-HAp) (m-HAp/ECG);

${ }^{j}$ Electrochemically reduced graphene oxide-gold nanoparticles;

${ }^{\mathrm{k}}$ Graphene with gold nanoparticles (G-Au 10\%);

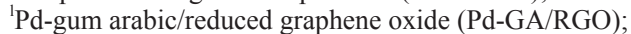

${ }^{\mathrm{m}}$ Perovskite $\left(\mathrm{SrTiO}_{3}\right)$ and reduced graphene oxide $(\mathrm{rGO})\left(\mathrm{rGO} / \mathrm{SrTiO}_{3}\right)$;

${ }^{\mathrm{n}} \beta$-Cyclodextrin functionalized reduced graphene oxide (RGO-CD-CS). 
This sensor is also utilized in the electrochemical detection of o-NPh and p-NPh in environmental samples. Liu et al exhibited the new improvement of a cyclodextrin functionalized graphene nanosheets CD-GNS sensor which is applied for electrochemical detection of o-NPh. CD-GNS nanocomposite was fabricated on a GCE to improve the electrochemical determination of o-NPh. CD-GNS/GCE electrode has mostly contributed to the electrochemical detection of o-NPh because the cyclodextrin is without problems resulted in a massive surface of GO nanosheets. This CD-GNS/GCE sensor confirmed a better detection limit of $0.3 \mu \mathrm{M}(\mathrm{S} / \mathrm{N}=3)$ in addition to proper selectivity, excellent stability and reproducibility for the detection of o-NPh [193].

$\mathrm{Xu}$ et al discovered that the synthesis of hydroxypropyl- $\beta$-cyclodextrin $(\mathrm{HP}-\beta-\mathrm{CD})$ functionalized with GO modified on GCE enhanced the selectivity and sensitivity for 4-NPh [170]. CD increases the water solubility, chemicalphysical properties and improvesthe electrocatalysis with GO. CD-GO nanocomposite is modified with GCE to give $\mathrm{CD}-\mathrm{GO} / \mathrm{GCE}$ for the electrocatalytic reduction of NPh derivatives. CD-GO/GCE electrode results in quick electron transfer and also the fast electrocatalytic activity of 2-NPh due to $\mathrm{CD}$ converting properties after functionalization on RGO. The prepared CD-GO/GCE showed good stability, selectivity and sensitivity in the determination of 2-NPh with cyclicvoltammetry methods of o-NPh with the detection limit of $1 \times 10^{-8} \mathrm{M}(\mathrm{S} / \mathrm{N}=3)$. CD-GO/GCE has been tested for anti-interference in the presence of cresol, o-chlorophenol, 2, 4, 6-trichlorophenol, o-aminophenol and catechol.

Yang et al reported a green approach of AuNPs bound on carboxylic graphene nanosheets (AuNPs-CGS) without an external reducing agent [194]. This AuNPs-CGS nanocompsoite is similarly modified with CDs to give $\beta$-CDAu@CGS nanocompsite. The CDs with thiol and amine functional groups easily forms an Au@CGS nanocomposite. $\beta$-CD-Au@CGS/GCE nanocompsite is efficiently coated on GCE to offer $\beta$-CD-Au@CGS/GCE which is applied for simultaneous electrochemical detection of 4-NPh and hydrqunione as shown in Figure 11. The $\beta$-CD-Au@CGS/ GCE delivered a low detection limit of 4-NP and HQ are $6.5 \mathrm{nM}$ and $3.8 \mathrm{nM}(\mathrm{S} / \mathrm{N}=3)$, respectively. $\beta-\mathrm{CD}-\mathrm{Au} @ \mathrm{CGS} /$ GCE sensor offers advantages such as high surface area, excellent conductivity, selectivity, high-host-guest molecular capability and anti-interference. Table 2 shows the electrochemical sensing of 4-NPh using GCE modified with various nanomaterials.

\section{Conclusions and future outlook}

In this review the recently published literature for the electrocatalytic application of 4-NPh using graphene based nanocomposite has been discussed. The electrochemical determination of 4-NPh has been achieved by cyclicvoltammetry methods and enhancement of sensitivity and selectivity has been observed with GO nanocomposites modified on GCE. Although, GO materials showed a low detection limit in the electrochemical sensing of 4-NPh by using modified GCE with electrochemical techniques method. Graphene based nanocomposites have delivered the good interaction between the modified GCE and 4-NPh, stability of the modified electrode, reproducibility of the modified on GCE electrode, selectivity and sensitivity of the modified GCE electrode and finally modified electrode to apply for electrochemical sensing of other interference such as HQ, TNP, TNT, APh, o-NPh. The aim of the review was to show that, Graphene nanocomposite materials are utilized for the electrochemical determination of 4-NPh with selectivity and sensitivity toward the 4-NPh in environmental samples. A variety of GO based nanocomposites have been used for the electrochemical application of 4-NPh and the GO based nanomaterials such GO and rGO. Metal nanoparticles with GO, Metal oxide with GO materials, polymer with GO, N-doped graphene oxide materials, cyclodextrin functionalized with graphene oxide. These materials have developed the new modified sensor to increase the electrochemical determination of 4-NPh and long time stability, sensitivity, selectivity and reproducibility. For the aim of future work, more novel GO based materials are needed for the development of electrochemical detection of 4-NPh sensing with good sensitivity and selectivity for sensors in practical applications. These materials can result in a good modified GCE electrode and good sensor system for the determination of $4-\mathrm{NPh}$ in the near future.

\section{Acknowledgements}

This work supported financially by a University of Johannesburg Research Grand programme. 


\section{References}

[1] Jamal A, Rahman MM, Khan SB, Faisal M, Akhtar K, Rub MA, et al. Cobalt doped antimony oxide nano-particles based chemical sensor and photo-catalyst for environmental pollutants. Applied Surface Science. 2012; 261: 52-58.

[2] Stanca SE, Popescu IC, Oniciu L. Biosensors for phenol derivatives using biochemical signal amplification. Talanta. 2003; 61(4): 501-507.

[3] Kumar S, Prasad S, Yadav KK, Shrivastava M, Gupta N, Nagar S, et al. Hazardous heavy metals contamination of vegetables and food chain: Role of sustainable remediation approaches-A review. Environmental Research. 2019; 179(A): 108792 .

[4] Kamyab H, Chelliapan S, Din MF, Shahbazian-Yassar R, Rezania S, Khademi T, et al. Evaluation of Lemna minor and Chlamydomonas to treat palm oil mill effluent and fertilizer production. Journal of Water Process Engineering. 2017; 17: 229-236.

[5] Khudhair AB, Hadibarata T, Yusoff AR, Teh ZC, Adnan LA, Kamyab H. Pyrene metabolism by new species isolated from soil Rhizoctonia zeae SOL3. Water Air and Soil Pollution. 2015; 226(186): 1-9.

[6] Khan SB, Akhtar K, Rahman MM, Asiri AM, Seo J, Alamry KA, et al. Thermally and mechanically stable green environmental composite for chemical sensor applications. New Journal of Chemistry. 2012; 36: 2368-2375.

[7] Jain RK, Kapur M, Labana S, Lal B, Sharma PM, Bhattacharya D, et al. Microbial diversity: Application of microorganisms for the biodegradation of xenobiotics. Current Science. 2005; 89(1): 101-112.

[8] Rahman MM, Jamal A, Khan SB, Faisal M. Characterization and applications of as-grown $\beta-\mathrm{Fe}_{2} \mathrm{O}_{3}$ nanoparticles prepared by hydrothermal method. Journal of Nanoparticle Research. 2011; 13: 3789-3799.

[9] Faisal M, Khan SB, Rahman MM, Jamal A. Synthesis, characterizations, photocatalytic and sensing studies of ZnO nanocapsules. Applied Surface Science. 2011; 258(2): 672-677.

[10] Schummer C, Groff C, Chami JA, Jaber F, Millet M. Analysis of phenols and nitrophenols in rainwater collected simultaneously on an urban and rural site in east of France. Science of the Total Environment. 2009; 407(21): 56375643.

[11] Buikema AL, McGimres MJ, Cairns J. Phenolics in aquatic ecosystems: a selected review of recent literature. Marine Environmental Research. 1979; 2(2): 87-181.

[12] Wang P, Xiao J, Liao A, Li P, Guo M, Xia Y. Electrochemical determination of 4-nitrophenol using uniform nanoparticle film electrode of glass carbon, fabricated facilely by square wave potential pulses. Electrochimica Acta. 2015; 176: 448-455.

[13] Xu XM, Liu Z, Zhang X, Duan S, Xu S, Zhou CL. Cyclodextrin functionalized mesoporous silica for electrochemical selective sensor: Simultaneous determination of nitrophenol isomers. Electrochimica Acta. 2011; 58(1): 142-149.

[14] Wei Y, Kong LT, Yang R, Wang L, Liu JH, Huang XJ. Single-walled carbon nanotube/pyrenecyclodextrin nanohybrids for ultra-highly sensitive and selective detection of p-nitrophenol. Langmuir. 2011; 27(16): 1029510301.

[15] Zhang WM, Chen JL, Pan BC, Chen Q, He MY, Zhang QX. Modeling cooperative adsorption of aromatic compounds in aqueous solutions to nonpolar adsorbent. Separation and Purification Technology. 2006; 49(2): 130135.

[16] Orshansky F, Narkis N. Characteristics of organics removal by PACT simultaneous adsorption and biodegradation. Water Research. 1997; 31(3): 391-398.

[17] Li AM, Zhang QX, Zhang GC, Chen JL, Fei ZH, Liu FQ. Adsorption of phenolic compounds from aqueous solutions by a water-compatible hyper cross linked polymeric adsorbent. Chemosphere. 2002; 47(9): 981-989.

[18] Aksu Z, Yener J. A comparative adsorption/biosorption study of mono-chlorinated phenols onto various sorbents. Waste Management. 2001; 21(8): 695-702.

[19] Naden BJ. Competitive adsorption of surfactant foaming agents to nanoclays added to cement foams for enhanced strength. Materials and Structures. 2016; 49: 1667-1675.

[20] Ali I, Gupta VK. Advances in water treatment by adsorption technology. Nature Protocols. 2006; 1: 2661-2667.

[21] Tadros TF. Adsorption of surfactants and polymeric surfactants at the solid/liquid interface. Applied Surfactants: Principles and Applications. 2005. p.85-114. Available from: https://doi.org/10.1002/3527604812.ch5.

[22] Pan C, Du W, Zhang WM, Zhang X, Zhang QR, Pan BJ, et al. Improved adsorption of 4-nitrophenol onto a novel hyper-cross-linked polymer. Environmental Science and Technology. 2007; 41(14): 5057-5062.

[23] Salehi Z, Rasouli A, Doosthosseini H. p-nitrophenol degradation kinetics and mass transfer study by ralstonia 
eutropha as a whole cell biocatalyst. Polycyclic Aromatic Compounds. 2021; 41(2): 292-305.

[24] Min J, Zhang JJ, Zhou NY. The gene cluster for para-nitrophenol catabolism is responsible for 2-chloro-4nitrophenol degradation in Burkholderia sp. Strain SJ98. Applied and Environmental Microbiology. 2014; 80(19): 6212-6222.

[25] Oturan MA, Peiroten J, Chartrin P, Acher AJ. Complete destruction of p-Nitrophenol in aqueous medium by electro-fenton method. Environmental Science and Technology. 2000; 34(16): 3474-3479.

[26] Osin OA, Yu T, Cai X, Jiang Y, Peng G, Cheng X, et al. Photocatalytic degradation of 4-nitrophenol by C, N-TiO 2 : Degradation efficiency vs. embryonic toxicity of the resulting compounds. Frontiers in Chemistry. 2018; 6: 192.

[27] Xie F, Xu Y, Xia K, Jia C, Zhang P. Alternate pulses of ultrasound and electricity enhanced electrochemical process for p-nitrophenol degradation. Ultrasonics Sonochemistry. 2016; 28: 199-206.

[28] Arora PK, Srivastava A, Singh VP. Bacterial degradation of nitrophenols and their derivatives. Journal of Hazardous Materials. 2014; 266: 42-59.

[29] Wang TC, Lu N, Li J, Wu Y. Plasma-TiO 2 catalytic method for high-efficiency remediation of p-nitrophenol contaminated soil in pulsed discharge. Environmental Science \& Technology. 2011; 45(21): 9301-9307.

[30] Ruan M, Song P, Liu J, Li E, Xu W. Highly efficient regeneration of deactivated Au/C catalyst for 4-Nitrophenol reduction. Journal of Physical Chemistry C. 2017; 121(46): 25882-25887.

[31] Wang C, Salmon L, Li Q, Igartua ME, Moya S, Ciganda R, et al. From mono to tris-1,2,3-triazole-stabilized gold nanoparticles and their compared catalytic efficiency in 4-Nitrophenol reduction. Inorganic Chemistry. 2016; 55(13): 6776-6780.

[32] Saran S, Manjari G, Devipriya SP. Synergistic eminently active catalytic and recyclable Ag, Cu and Ag-Cu alloy nanoparticles supported on $\mathrm{TiO}_{2}$ for sustainable and cleaner environmental applications: A phytogenic mediated synthesis. Journal of Cleaner Production. 2018; 177: 134-143.

[33] Corbett JF. An historical review of the use of dye precursors in the formulation of commercial oxidation hair dyes. Dyes and Pigments. 1999; 41(1-2): 127-136.

[34] Keum YS, Li QX. Reduction of nitroaromatic pesticides with zero-valent iron. Chemosphere. 2004; 54(3): 255263.

[35] Klausen J, Ranke J, Schwarzenbach RP. Influence of solution composition and column aging on the reduction of nitroaromatic compounds by zero-valent iron. Chemosphere. 2001; 44(4): 511-517.

[36] Kulkarni M, Chaudhari A. Microbial remediation of nitro-aromatic compounds: An overview. Journal of Environmental Management. 2007; 85(2): 496-512.

[37] Melián JAH, Martín-Rodriguez AJ, Méndez JAO, Araña J, Rodríguez JMD, Pérez-Peña J. Degradation and detoxification of 4-nitrophenol by advanced oxidation technologies and bench-scale constructed wetlands. Journal of Environmental Management. 2012; 105: 53-60.

[38] Dolan T, Howsam P, Parsons DJ, Whelan MJ. Is the EU drinking water directive standard for pesticides in drinking water consistent with the precautionary principle. Environmental Science \& Technology. 2013; 47(10): 4999-5006.

[39] Sethunathan N, Siddaramappa R, Rajaram KP, Barik S, Wahid PA. Parathion: Residues in soil and water. Residue Reviews. 1977; 68: 91-122.

[40] Galeano-Díaz T, Guiberteau-Cabanillas A, Mora-Díez N, Parrilla-Vázquez P, Salinas-López F. Rapid and sensitive determination of 4-nitrophenol, 3-methyl-4-nitrophenol, 4,6-dinitro-o-cresol, parathion-methyl, fenitrothion, and parathion-ethyl by liquid chromatography with electrochemical detection. Journal of Agricultural and Food Chemistry. 2000; 48(10): 4508-4513.

[41] Guo XF, Wang ZH, Zhou SP. The separation and determination of nitrophenol isomers by high-performance capillary zone electrophoresis. Talanta. 2004; 64(1): 135-139.

[42] Norwitz G, Nataro N, Keliher PN. Study of the steam distillation of phenolic compounds using ultraviolet spectrometry. Analytical Chemistry. 1986; 58: 639-641.

[43] Belloli R, Barletta B, Bolzacchini E, Meinardi S, Orlandi M, Rindone B. Determination of toxic nitrophenols in the atmosphere by high-performance liquid chromatography. Journal of Chromatography A. 1999; 846(1-2): $277-281$.

[44] Manera M, Miró M, Estela JM, Cerdà V, Segundo MA, Lima JLFC. Flow through solid-phase reflectometric method for simultaneous multiresidue determination of nitrophenol derivatives. Analytica Chimica Acta. 2007; 600(1-2): 155-163.

[45] Tingry S, Innocent C, Touil S, Deratani A, Seta P. Carbon paste biosensor for phenol detection of impregnated tissue: Modification of selectivity by using cyclodextrin-containing PVA membrane. Materials Science and Engineering: C. 2006; 26(1-2): 222-226.

[46] Li J, Kuang D, Feng Y, Zhang F, Xu Z, Liu M. A graphene oxide-based electrochemical sensor for sensitive determination of 4-nitrophenol. Journal of Hazardous Materials. 2012; 201-202: 250-259. 
[47] Xu Y, Wang Y, Ding Y, Luo L, Liu X, Zhang Y. Determination of p-nitrophenol on carbon paste electrode modified with a nanoscaled compound oxide Mg (Ni) FeO. Journal of Applied Electrochemistry. 2013; 43(7): 679687.

[48] Yang Y-L, Unnikrishnan B, Chen S-M. Amperometric determination of 4-nitrophenol at multi-walled carbon nanotube-poly(diphenylamine) composite modified glassy carbon electrode. International Journal of Electrochemical Science. 2011; 6(9): 3902-3912.

[49] Yin H, Ma Q, Zhou Y, Ai S, Zhu L. Electrochemical behavior and voltammetric determination of 4-aminophenol based on graphene-chitosan composite film modified glassy carbon electrode. Electrochimica Acta. 2010; 55(23): $7102-7108$.

[50] de Lima CA, da Silva PS, Spinelli A. Chitosan-stabilized silver nanoparticles for voltammetric detection of nitrocompounds. Sensors and Actuators B: Chemical. 2014; 196: 39-45.

[51] Yang L, Fan S, Deng G, Li Y, Ran X, Zhao H, Li C-P. Bridged $\beta$-cyclodextrinfunctionalized MWCNT with higher supramolecular recognition capability: The simultaneous electrochemical determination of three phenols. Biosensors \& Bioelectronics. 2015; 68C: 617-625.

[52] Janata J. Centennial retrospective on chemical sensors. Analytical Chemistry. 2001; 73(5): 150A-153A.

[53] Janata J, Bezegh A. Chemical sensors. Analytical Chemistry. 1988; 60: 62-74.

[54] Widrig CA, Porter MD, Ryan MD, Strein TG, Ewing AG. Dynamic electrochemistry: Methodology and application. Analytical Chemistry. 1990; 62(12): 1R-20R.

[55] Edmonds TE. Chemical Sensors. New York: Chapman and Hall; 1988.

[56] Janata J. Principles of Chemical Sensors. New York; 1989.

[57] Wang J. Electroanalytical techniques in clinical chemistry and laboratory medicine. New York: VCH; 1988.

[58] Shao Y, Wang J, Wu H, Liu J, Aksay IA, Lin Y. Graphene based electrochemical sensors and biosensors: A review. Electroanalysis. 2010; 22(10): 1027-1036.

[59] Joo S, Brown RB. Chemical sensors with integrated electronics. Chemical Reviews. 2008; 108(2): 638-651.

[60] Wang Y, Xu H, Zhang J, Li G. Electrochemical sensors for clinic analysis. Sensors. 2008; 8(4): $2043-2081$.

[61] Xu X, Liu Z, Zhang X, Duan S, Xu S, Zhou C. $\beta$-Cyclodextrin functionalized mesoporous silica for electrochemical selective sensor: Simultaneous determination of nitrophenol isomers. Electrochimica Acta. 2011; 58: 142-149.

[62] Nicholson RS, Shain I. Experimental verification of an ECE mechanism for the reduction of p-nitrosophenol, using stationary electrode polarography. Analytical Chemistry. 1965; 37(2): 178-190.

[63] Nicholson RS, Wilson JM, Olmstead ML. Polarographic theory for an ECE mechanism application to reduction of p-nitrosophenol. Analytical Chemistry. 1966; 38(4): 542-545.

[64] Rameshkumar P, Ramaraj R. Electroanalysis of nitrobenzene derivatives and nitrite ions using silver nanoparticles deposited silica spheres modified electrode. Journal of Electroanalytical Chemistry. 2014; 731(1): 72-77.

[65] Thirumalraj B, Rajkumar C, Chen SM, Lin K-Y. Determination of 4-nitrophenol in water by use of a screenprinted carbon electrode modified with chitosan-crafted $\mathrm{ZnO}$ nanoneedles. Journal of Colloid and Interface Science. 2017; 499(1): 83-92.

[66] Karuppiah C, Palanisamy S, Chen S-M, Emmanuel R, Ali MA, Muthukrishnan P, et al. Green biosynthesis of silver nanoparticles and nanomolar detection of $p$-nitrophenol. Journal of Solid State Electrochemistry. 2014; 18(7): 1847-1854.

[67] da Silva PS, Gasparini BC, Magosso HA, Spinelli A. Gold nanoparticles hosted in a water-soluble silsesquioxane polymer applied as a catalytic material onto an electrochemical sensor for detection of nitrophenol isomers. Journal of Hazardous Materials. 2014; 273: 70-77.

[68] Shaha F, Akhtar M, Aftab S, Shah AH, Kraatz H-B. Gold copper alloy nanoparticles (Au-Cu NPs) modified electrode as an enhanced electrochemical sensing platform for the detection of persistent toxic organic pollutants. Electrochimica Acta. 2017; 241: 281-290.

[69] Bashami RM, Hameed A, Aslam M, Ismail IMI, Soomro MT. The suitability of ZnO film-coated glassy carbon electrode for the sensitive detection of 4-nitrophenol in aqueous medium. Analytical Methods. 2015; 7(5): 17941801.

[70] Veeramani V, Sivakumar M, Chen S-M, Madhu R, Dai Z-C, Miyamoto N. A facile electrochemical synthesis strategy for $\mathrm{Cu}_{2} \mathrm{O}$ (cubes, sheets and flowers) microstructured materials for sensitive detection of 4-nitrophenol. Analytical Methods. 2016; 8(30): 5906-5910.

[71] Yin H, Zhou Y, Ai S, Ma Q, Zhu L, Lu L. Electrochemical oxidation determination and voltammetric behaviour of 4-nitrophenol based on $\mathrm{Cu}_{2} \mathrm{O}$ nanoparticles modified glassy carbon electrode. International Journal of Environmental Analytical Chemistry. 2012; 92(6): 1-13.

[72] Wu J, Wang Q, Umar A, Sun S, Huang L, Wang J, et al. Highly sensitive p-nitrophenol chemical sensor based on 
crystalline $\alpha-\mathrm{MnO}_{2}$ nanotubes. New Journal of Chemistry. 2014; 38(9): 4420-4426.

[73] Pana L, Chena Y, Wang F. Synthesis of nanostructured $\mathrm{M} / \mathrm{Fe}_{3} \mathrm{O}_{4}(\mathrm{M}=\mathrm{Ag}, \mathrm{Cu})$ composites using hexamethylentetramine and their electrocatalytic properties. Materials Chemistry and Physics. 2012; 134(1): $177-182$.

[74] Li S, Du D, Huang J, Tu H, Yang Y, Zhang A. One-step electrodeposition of a molecularly imprinting chitosan/ phenyltrimethoxysilane/AuNPs hybrid film and its application in the selective determination of $p$-nitrophenol. Analyst. 2013; 138(9): 2761-2768.

[75] Chang G, Luo Y, Lu W, Qin X, Asiri AM, Al-Youbi AO, et al. Ag nanoparticles decorated polyaniline nanofibers: synthesis, characterization, and applications toward catalytic reduction of 4-nitrophenol and electrochemical detection of $\mathrm{H}_{2} \mathrm{O}_{2}$ and glucose. Catalysis Science \& Technology. 2012; 2(4): 800-806.

[76] Yao C, Sun H, Fu H-F, Tan Z-C. Sensitive simultaneous determination of nitrophenol isomers at poly(paminobenzene sulfonic acid) film modified graphite electrode. Electrochimica Acta. 2015; 156(20): 163-170.

[77] Giribabu K, Suresh R, Manigandan R, Munusamy S, Kumar SP, Muthamizh S, et al. Nanomolar determination of 4-nitrophenol based on a poly(methylene blue)-modified glassy carbon electrode. Analyst. 2013; 138(19): 58115818.

[78] Yang Y-L, Unnikrishnan B, Chen S-M. Electrochemical determination of 4-nitrophenol using a single-wall carbon nanotube film-coated glassy carbon electrode. Microchimica Acta. 2004; 148: 87-92.

[79] Liu B, Wang T, Yin C, Wei ZJ. Electrochemical analysis of $p$-nitrophenol in acidic or alkaline medium using silver nanoparticle decorated multi-walled carbon nanotubes. Journal of Materials Science. 2014; 49(15): 5398-5405.

[80] Serrà A, Alcobé X, Sort J, Nogués J, Vallés E. Highly efficient electrochemical and chemical hydrogenation of 4-nitrophenol using recyclable narrow mesoporous magnetic CoPt nanowires. Journal of Materials Chemistry A. 2016; 4(40): 15676-15687.

[81] Wiench P, Grzyb B, González Z, Menéndez R, Handke B, Gryglewicz G. pH robust electrochemical detection of 4-nitrophenol on a reduced graphene oxide modified glassy carbon electrode. Journal of Electroanalytical Chemistry. 2017; 787(15): 80-87.

[82] Luo J, Cong J, Liu J, Gao Y, Liu X. A facile approach for synthesizing molecularly imprinted graphene for ultrasensitive and selective electrochemical detecting 4-nitrophenol. Analytica Chimica Acta. 2015; 864(15): 7484.

[83] Ikhsan NI, Rameshkumar P, Huang NM. Controlled synthesis of reduced graphene oxide supported silver nanoparticles for selective and sensitive electrochemical detection of 4-nitrophenol. Electrochimica Acta. 2016; 192: 392-399.

[84] Tang Y, Huang R, Liu C, Yang S, Lu Z, Luo S. Electrochemical detection of 4-nitrophenol based on a glassy carbon electrode modified with a reduced graphene oxide/Au nanoparticle composite. Analytical Methods. 2013; 5(20): 5508-5514.

[85] Zaidi SA, Shin JH. A novel and highly sensitive electrochemical monitoring platform for 4-nitrophenol on $\mathrm{MnO}_{2}$ nanoparticles modified graphene surface. RSC Advances. 2015; 5: 88996-89002.

[86] Zheng B, Li C, Li Y, Gu Y, Yan X, Tang L, et al. One-step electrochemical preparation of a reduced graphene oxide/poly(sulfosalicylic acid) nanocomposite film for detection of acetaminophen and its application in human urine and serum studies. Analytical Methods. 2015; 7(19): 8248-8254.

[87] Deng P, Xu Z, Li J. Simultaneous voltammetric determination of 2-nitrophenol and 4-nitrophenol based on an acetylene black paste electrode modified with a graphene-chitosan composite. Microchimica Acta. 2014; 181(910): 1077-1084.

[88] Peng D, Zhang J, Qin D, Chen J, Shan D, Lu X. An electrochemical sensor based on polyelectrolyte-functionalized graphene for detection of 4-nitrophenol. Journal of Electroanalytical Chemistry. 2014; 734(15): 1-6.

[89] Rameshkumar P, Yusoff N, Ming HN, Sajab MS. Microwave synthesis of reduced graphene oxide decorated with silver nanoparticles for electrochemical determination of 4-nitrophenol. Ceramics International. 2016; 42(16): 18813-18820.

[90] Nehru R, Gopi PK, Chen SM. Enhanced sensing of hazardous 4-nitrophenol by a graphene oxide-TiO ${ }_{2}$ composite: environmental pollutant monitoring applications. New Journal of Chemistry. 2020; 44(11): 4590-4603.

[91] Tang Y, Huang R, Liu C, Yang S, Lu Z, Luo S. Electrochemical detection of 4-nitrophenol based on a glassy carbon electrode modified with a reduced graphene oxide/Au nanoparticle composite. Analytical Methods. 2013; 5(30): 5508-5514.

[92] Karthik R, Hou YS, Chen SM, Elangovan A, Ganesan M, Muthukrishnan P. Eco-friendly synthesis of Ag-NPs using Cerasus serrulata plant extract-Its catalytic, electrochemical reduction of 4-NPh and antibacterial activity. Journal of Industrial and Engineering Chemistry. 2016; 37(25): 330-339.

[93] de Lima CA, da Silva PS, Spinelli A. Chitosan-stabilized silver nanoparticles for voltammetric detection of 
nitrocompounds. Sensors and Actuators B: Chemical. 2014; 196: 39-45.

[94] Dinesh B, Saraswathi R. Electrochemical synthesis of nanostructured copper-curcumin complex and its electrocatalytic application towards reduction of 4-nitrophenol. Sensors and Actuators B: Chemical. 2017; 253: 502-512.

[95] Wiench P, Grzy B, González Z, Menéndez R, Handke B, Gryglewicz G. pH robust electrochemical detection of 4-nitrophenol on a reduced graphene oxide modified glassy carbon electrode. Journal of electroanalytical chemistry. 2017; 787: 80-87.

[96] de Oliveira RM, Santos NG, Lima KCMS, Kubota LT, Damos FS, Luz RDCS, et al. Highly sensitive p-nitrophenol determination employing a new sensor based on N-methylphenazoniummethyl sulfate and graphene: analysis in natural and treated waters. Sensors and Actuators B: Chemical. 2015; 221: 740-749.

[97] Li C, Wu Z, Yang H, Deng L, Chen X. Reduced graphene oxide-cyclodextrin-chitosan electrochemical sensor: effective and simultaneous determination of o-and pnitrophenols. Sensors and Actuators B: Chemical. 2017; 251: 446-454.

[98] Thirumalraj B, Rajkumar C, Chen S-M, Lin K-Y. Determination of 4-nitrophenol in water by use of a screenprinted carbon electrode modified with chitosan-crafted $\mathrm{ZnO}$ nanoneedles. Journal of Colloid and Interface Science. 2017; 499: 83-92.

[99] Wang P, Xiao J, Liao A, Li P, Guo M, Xia Y, et al. Electrochemical determination of 4-nitrophenol using uniform nanoparticle film electrode of glass carbon fabricated facilely by square wave potential pulses. Electrochimica Acta. 2015; 176: 448-455.

[100]Yin H, Zhou Y, Ai S, Liu X, Zhu L, Lu L. Electrochemical oxidative determination of 4-nitrophenol based on a glassy carbon electrode modified with a hydroxyapatite nanopowder. Microchimica Acta. 2010; 169(1): 87-92.

[101]Chen J, Yang G, Chen M, Li W. Sensitive determination of 4-nitrophenol based on multi-walled carbon nano-tube/ ionic liquid/chitosan composite film modified electrode. Journal of Electrochemistry. 2009; 45(11): 1287-1291.

[102]Hashemi SA, Mousavi SM, Bahrani S, Ramakrishna S. Integrated polyaniline with graphene oxide-iron tungsten nitride nanoflakes as ultrasensitive electrochemical sensor for precise detection of 4-nitrophenol within aquatic media. Journal of Electroanalytical Chemistry. 2020; 873: 114406.

[103]Choi W, Lahiri I, Seelaboyina R, Kang YS. Synthesis of graphene and its applications: A review. Critical Reviews in Solid State and Materials Sciences. 2010; 35(1): 52-71.

[104]Kampouris DK, Banks CE. Exploring the physicoelectrochemical properties of graphene. Chemical Communications. 2010; 46(47): 8986-8988.

[105]Wu S, He Q, Tan C, Wang Y, Zhang H. Graphene-based electrochemical sensors. Small. 2013; 9: 1160-1172.

[106]Ambrosi A, Chua CK, Bonanni A, Pumera M. Electrochemistry of graphene and related materials. Chemical Reviews. 2014; 114(14): 7150-7188.

[107]Yuan W, Zhou Y, Li Y, Li C, Peng H, Zhang J, et al. The edge-and basal-plane-specific electrochemistry of a single-layer graphene sheet. Scientific Reports. 2013; 3(1): 2248.

[108]Brownson DA, Munro LJ, Kampouris DK, Banks CE. Electrochemistry of graphene: Not such a beneficial electrode material? RSC Advances. 2011; 1(6): 978-988.

[109]Brownson DA, Foster CW, Banks CE. The electrochemical performance of graphene modified electrodes: An analytical perspective. The Analyst. 2012; 137(8): 1815-1823.

[110]Pumera M. Graphene-based nanomaterials and their electrochemistry. Chemical Society Reviews. 2010; 39(11): 4146-4157.

[111]Chen XM, Wu GH, Jiang YQ, Wang Y-R, Chen X. Graphene and graphene-based nanomaterials: The promising materials for bright future of electroanalytical chemistry. The Analyst. 2011; 136: 4631-4640.

[112]Zhou M, Zhai Y, Dong S. Electrochemical sensing and biosensing platform based on chemically reduced graphene oxide. Analytical Chemistry. 2009; 81(14): 5603-5613.

[113]Ambrosi A, Pumera M. Nanographite impurities dominate electrochemistry of carbon nanotubes. Chemistry- $A$ European Journal. 2010; 16(36): 10946-10949.

[114]Hummers WS, Offeman RE. Preparation of graphitic oxide. Journal of the American Chemical Societ. 1958; 80(6): 1339.

[115]Chen L, Tang Y, Wang K, Liu C, Luo S. Direct electrodeposition of reduced graphene oxide on glassy carbon electrode and its electrochemical application. Electrochemistry Communications. 2011; 13(2): 133-137.

[116]Guo H-L, Wang X-F, Qian Q-Y, Wang F-B, Xia X-H. A green approach to the synthesis of graphene nanosheets. ACS Nano. 2009; 3(9): 2653-2659.

[117]Liu C, Wang K, Luo S, Tang Y, Chen L. Direct electrodeposition of graphene enabling the one-step synthesis of graphene-metal nanocomposite films. Small. 2011; 7(9): 1203-1206. 
[118]Xue ZH, Hou HH, Rao HH, Hu CX, Zhou XB, Liu XH, et al. A green approach for assembling graphene films on different carbon-based substrates and their electrocatalysis toward nitrite. RSC Advances. 2015; 5(46): 3670736714.

[119]Hirata M, Gotou T, Horiuchi S, Fujiwara M, Ohba M. Thin-film particles of graphite oxide 1: High-yield synthesis and flexibility of the particles. Carbon. 2004; 42(14): 2929-2937.

[120]Privett BJ, Shin JH, Schoensch MH. Electrochemical sensors. Analytical Chemistry. 2010; 82: 4723-4741.

[121]Hrapovic S, Liu Y, Male KB, Luong JH. Electrochemical biosensing platforms using platinum nanoparticles and Carbon Nanotubes. Analytical Chemistry. 2004; 76(4): 1083-1088.

[122]Guo S, Dong S. Graphene nanosheet: Synthesis, molecular engineering, thin film, hybrids, and energy and analytical applications. Chemical Society Reviews. 2011; 40(5): 2644-2672.

[123]Robinson JT, Perkins FK, Snow ES, Wei Z, Sheehan PE. Reduced graphene oxide molecular sensors. Nano Letters. 2008; 8(10): 3137-3140.

[124]Bogue R. Graphene sensors: A review of recent developments. Sensor Review. 2014; 34(3): 233-238.

[125]Zhou M, Wang Y, Zhai Y, Zhai J, Ren W, Wang F, et al. Controlled synthesis of large-area and patterned electrochemically reduced graphene oxide films. Chemistry-A European Journal. 2009; 15(25): 6116-6120.

[126]Wu C, Cheng Q, Wu K. Electrochemical functionalization of n-methyl-2-pyrrolidone-exfoliated graphene nanosheets as highly sensitive analytical platform for phenols. Analytical Chemistry. 2015; 87(6): 3294-3299.

[127]Rao H, Guo W, Hou H, Wang H, Yin B, Xue Z, et al. Electroanalytical investigation of p-nitrophenol with dual electroactive groups on a reduced graphene oxide modified glassy carbon electrode. International Journal of Electrochemical Science. 2017; 12: 1052-1063.

[128]Shao YY, Wang J, Engelhard M, Wang CM, Lin YM. Facile and controllable electrochemical reduction of graphene oxide and its applications. Journal of Materials Chemistry. 2010; 20(4): 743-748.

[129]Zhou M, Wang YL, Zhai YM, Zhai JF, Ren W, Wang F, et al. Controlled synthesis of large-area and patterned electrochemically reduced graphene oxide films. Chemistry-A European Journal. 2009; 15(25): 6116-6120.

[130]Lates V, Gligor D, Muresan LM, Popescu IC. Comparative investigation of NADH electrooxidation at graphite electrodes modified with two new phenothiazine derivatives. Journal of Electroanalytical Chemistry. 2011; 661: 192-197.

[131]Oliveira RMD, Santos NG, Alves LDA, Lima KCMS, Kubota LT, Damos FS, et al. Highly sensitive p-nitrophenol determination employing a new sensor based on N-Methylphenazonium methyl sulfate and graphene: Analysis in natural and treated waters. Sensors and Actuators B: Chemical. 2015; 221(31): 740-749.

[132]Boitumelo JM, Kamalakannan R, Mutum BK, Lerotholi T, Jonescd G, Coville NJ. Time-dependent evolution of the nitrogen configurations in N-doped graphene films. RSC Advances. 2016; 6(108): 106914-106920.

[133]Zhao Y, Hu C, Hu Y. A versatile, ultralight, nitrogen-doped graphene framework. Angewandte Chemie International Edition. 2012; 51(45): 11371-11375.

[134]Choi CH, Chung MW, Kwon HC, Park SH, Woo SI. N-doped graphene as highly active catalysts for oxygen reduction reactions in acidic media. Journal of Materials Chemistry A. 2013; 1(11): 3694-3699.

[135]Jeong HM, Lee JM, Shin WH. Nitrogen-doped graphene for high-performance ultracapacitors and the importance of nitrogen-doped sites at basal planes. Nano Letters. 2011; 11(6): 2472-2477.

[136]Luo G, Liu L, Zhang J. Hole defects and nitrogen doping in graphene: Implication for supercapacitor applications. ACS Applied Materials \& Interfaces. 2013; 5: 11184-11193.

[137]Usachov D, Vilkov O, Gruneis A, Haberer D, Fedorov A, Adamchuk V, et al. Nitrogen-doped graphene: Efficient growth, structure, and electronic properties. Nano Letters. 2011; 11(12): 5401-5407.

[138]Fan W, Xia YY, Tjiu WW. Nitrogen-doped graphene hollow nanospheres as novel electrode materials for supercapacitor applications. Journal of Power Sources. 2013; 243: 973-981.

[139]Lv R, Terrones M. Towards new graphene materials: Doped graphene sheets and nanoribbons. Materials Letters. 2012; 78: 209-218.

[140]Liu H, Liu Y, Zhu D. Chemical doping of graphene. Journal of Materials Chemistry. 2011; 21(10): 3335-3345.

[141]Gan T, Hu S. Electrochemical sensors based on graphene materials. Microchimica Acta. 2011; 175(1): 1-19.

[142]Deng D, Pan X, Yu L, Cui Y, Jiang Y, Qi J, et al. Toward n-doped graphene via solvothermal synthesis. Chemistry of Materials. 2011; 23(5): 1188-1193.

[143]Li N, Wang Z, Zhao K, Shi Z, Gu Z, Xu S. Large scale synthesis of n-doped multi-layered graphene sheets by simple arc-discharge method. Carbon. 2010; 48(1): 255-259.

[144]Zhang C, Fu L, Liu N, Lu M, Wang Y, Liu Z. Synthesis of nitrogen-doped graphene using embedded carbon and nitrogen sources. Advanced Materials. 2011; 23(8): 1020-1024.

[145]Wei D, Liu Y, Wang Y, Zhang H, Huang L, Yu G. Synthesis of N-doped graphene by chemical vapor deposition 
and its electrical properties. Nano Letters. 2009; 9(5): 1752-1758.

[146]Jin Z, Yao J, Kittrell C, Tour JM. Large-scale growth and characterizations of nitrogen-doped monolayer graphene sheets. ACS Nano. 2011; 5(5): 4112-4117.

[147]Sheng ZH, Shao L, Chen J-J, Bao W-J, Wang F-B, Xia X-H, et al. Catalyst-free synthesis of nitrogen-doped graphene via thermal annealing graphite oxide with melamine and its excellent electrocatalysis. ACS Nano. 2011; 5(6): 4350-4358.

[148]Wang X, Li X, Zhang L, Yoon Y, Weber PK, Wang H, et al. N-doping of graphene through electrothermal reactions with ammonia. Science. 2009; 324(5928): 768-771.

[149]Wang G, Jia LT, Zhu Y, Hou B, Li D-B, Sun Y-H. Novel preparation of nitrogen-doped graphene in various forms with aqueous ammonia under mild conditions. RSC Advances. 2012; 2(30): 11249-11252.

[150]Chen P, Yang JJ, Li S-S, Wang Z, Xiao T-Y, Qian Y-H, et al. Hydrothermal synthesis of macroscopic nitrogendoped graphene hydrogels for ultrafast supercapacitor. Nano Energy. 2013; 2(2): 249-256.

[151]Jafri RI, Rajalakshmi N, Ramaprabhu S. Nitrogen doped graphene nanoplatelets as catalyst support for oxygen reduction reaction in proton exchange membrane fuel cell. Journal of Materials Chemistry. 2010; 20(34): 71147117.

[152]Wang Y, Shao Y, Matson DW, Li J, Lin Y. Nitrogen-doped graphene and its application in electrochemical biosensing. ACS Nano. 2010; 4(4): 1790-1798.

[153]Zhang Y, Ge J, Wang L, Wang D, Ding F, Tao X, et al. Manageable n-doped graphene for high performance oxygen reduction reaction. Scientific Reports. 2013; 3: 2771.

[154]Giribabu K, Suresh R, Manigandan R, Praveen Kumar S, Muthamizh S, Munusamy S, et al. Preparation of nitrogen-doped reduced graphene oxide and its use in a glassy carbon electrode for sensing 4-nitrophenol at nanomolar levels. Microchimica Acta. 2014; 181(15-16): 1863-1870.

[155]Zhang Y, Wu L, Lei W, Xia X, Xia M, Hao Q. Electrochemical determination of 4-nitrophenol at polycarbazole/ N-doped graphene modified glassy carbon electrode. Electrochimica Acta. 2014; 146: 568-576.

[156]Dadkhah S, Ziaei E, Mehdinia A, Kayyal TB, Jabbari A. A glassy carbon electrode modified with aminofunctionalized graphene oxide and molecularly imprinted polymer for electrochemical sensing of bisphenol. Microchim Acta. 2016; 183: 1933-1941.

[157]Niyogi S, Bekyarova E, Itkis ME, McWilliams JL, Hamon MA, Haddon RC. Solution properties of graphite and graphene. Journal of the American Chemical Society. 2006; 128(24): 7720-7721.

[158]Shan C, Yang H, Han D, Zhang Q, Ivaska A, Niu L. Water-soluble graphene covalently functionalized by biocompatible poly-1-lysine. Langmuir. 2009; 25(20): 12030-12033.

[159]Si Y, Samulski ET. Synthesis of Water Soluble Graphene. Nano Letters. 2008; 8(6): 1679-1682.

[160]Kulkarni A, Mukhopadhyay N, Bhattacharyya AR, Panwar AS. Dispersion of non-covalently modified graphene in aqueous medium: A molecular dynamics simulation approach. RSC Advances. 2017; 7(8): 4460-4467.

[161]Peng D, Zhang J, Qin D, Chen J, Shan D, Lu X. An electrochemical sensor based on polyelectrolyte-functionalized graphene for detection of 4-nitrophenol. Journal of Electroanalytical Chemistry. 2014; 734: 1-6.

[162]Shi JJ, Yang GH, Zhu JJ. Sonoelectrochemical fabrication of PDDA-RGO-PdPt nanocomposites as electrocatalyst for DAFCs. Journal of Materials Chemistry. 2011; 21(20): 7343-7349.

[163]Zhang L, Shi HW, Wang C, Zhang KY. Preparation of a nanocomposite film from poly(diallydimethyl ammonium chloride) and gold nanoparticles by in-situ electrochemical reduction, and its application to SERS spectroscopy and sensing of ascorbic acid. Microchimica Acta. 2011; 173: 401-406.

[164]Alexeyeva N, Tammeveski K. Electroreduction of oxygen on gold nanoparticle/PDDA-MWCNT nanocomposites in acid solution. Analytica Chimica Acta. 2008; 618(2): 140-146.

[165]Liu K, Zhang J, Yang G, Wang C, Zhu J-J. Direct electrochemistry and electrocatalysis of hemoglobin based on poly(diallyldimethylammonium chloride) functionalized graphene sheets/room temperature ionic liquid composite film. Electrochemistry Communications. 2010; 12(3): 402-405.

[166]Wang L, Lu D, Yu S, Shi X, Wang C, Zhang Y. Voltammetric determination of alkannin using an Au nanoparticles-poly(diallyldimethylammonium chloride)-functionalized graphene nanocomposite film. Journal of Applied Electrochemistry. 2013; 43(8): 855-863.

[167]Wang S, Yu D, Dai L, Chang DW, Baek J-B. Polyelectrolyte-functionalized graphene as metal-free electrocatalysts for oxygen reduction. ACS Nano. 2011; 5(8): 6202-6209.

[168]Lu W, Ning R, Qin X, Zhang Y, Chang G, Liu S, et al. Synthesis of Au nanoparticles decorated graphene oxide nanosheets: noncovalent functionalization by TWEEN 20 in situ reduction of aqueous chloroaurate ions for hydrazine detection and catalytic reduction of 4-nitrophenol. Journal of Hazardous Materials. 2011; 197: $320-326$.

[169]Lu DB, Zhang Y, Wang LT, Lin SX, Wang CM, Chen XF. Sensitive detection of acetaminophen based on $\mathrm{Fe}_{3} \mathrm{O}_{4}$ 
nanoparticles-coated poly(diallyldimethylammonium chloride)-functionalized graphene nanocomposite film. Talanta. 2012; 88: 181-186.

[170]Xu C, Wang J, Wan L, Lin J, Wang X. Microwave-assisted covalent modification of graphene nanosheets with hydroxypropyl- $\beta$-cyclodextrin and its electrochemical detection of phenolic organic pollutants. Journal of Materials Chemistry. 2011; 21(28): 10463-10471.

[171]Bharath G, Veeramani V, Chen S-M, Madhu R, Raja MM, Balamurugan A, et al. Edge-carboxylated graphene anchoring magnetite-hydroxyapatite nanocomposite for an efficient 4-nitrophenol sensor. RSC Advances. 2015; 5(18): 13392-13401.

[172]Arfin T, Bushra R, Mohammad F. Electrochemical sensor for the sensitive detection of $o$-nitrophenol using graphene oxide-poly(ethyleneimine) dendrimer-modified glassy carbon electrode. Graphene Technology. 2016; 1: $1-15$.

[173]Yin H, Ma Q, Zhou Y, Ai S, Zhu L. Electrochemical behavior and voltammetric determination of 4-aminophenol based on graphene-chitosan composite film modified glassy carbon electrode. Electrochimica Acta. 2010; 55(23): $7102-7108$.

[174]Fan Y, Liu J-H, Yang C-P, Yu M, Liu P. Graphene-polyaniline composite film modified electrode for voltammetric determination of 4-aminophenol. Sensors and Actuators B: Chemical. 2011; 157(2): 669-674.

[175]Liu Y, Zhua L, Zhang Y, Tang H. Electrochemical sensor of 2,4-dinitrophenol by using composites of graphene oxide with surface molecular imprinted polymer. Sensors and Actuators B: Chemical. 2012; 171-172: 1151-1158.

[176]Li C, Wu Z, Yang H, Deng L, Chen X. Reduced graphene oxide-cyclodextrin-chitosan electrochemical sensor: effective and simultaneous determination of $o$-and $p$-Nitrophenols. Sensors and Actuators B: Chemical. 2017; 251: 446-454.

[177]Tang J, Zhang L, Han G, Liu Y, Tang W. Graphene-chitosan composite modified electrode for simultaneous detection of nitrophenol isomers. Journal of the Electrochemical Society. 2015; 162(10): B269-B274.

[178]Zheng B, Li C, Li Y, Gu Y, Yan X, Tang L, et al. One-step electrochemical preparation of a reduced graphene oxide/poly(sulfosalicylic acid) nanocomposite film for detection of acetaminophen and its application in human urine and serum studies. Analytical Methods. 2015; 7(19): 8248-8254.

[179]Yang G. One-pot preparation of reduced graphene oxide/silver nanocomposite and its application in the electrochemical determination of 4-Nitrophenol. International Journal of Electrochemical Science. 2015; 10: 96329640 .

[180]Noor M, Rameshkumar P, Yusuf N, Ming HN, Sajab MS. Microwave synthesis of reduced graphene oxide decorated with silver nanoparticles for electrochemical determination of 4-nitrophenol. Ceramics International. 2016; 42(16): 18813-18820.

[181]Ikhsan NZ, Rameshkumar P, Huang NM. Controlled synthesis of reduced graphene oxide supported silver nanoparticles for selective and sensitive electrochemical detection of 4-nitrophenol. Electrochimica Acta. 2016; 192: 392-399.

[182]Karuppiah C, Muthupandi K, Chen S-M, Ajmal Ali M, Palanisamy S, Rajan A, et al. Green synthesized silver nanoparticles decorated on reduced graphene oxide for enhanced electrochemical sensing of nitrobenzene in waste water samples. RSC Advances. 2015; 5(39): 31139-31146.

[183]Tang Y, Huang R, Liu C, Yang S, Lu Z, Luo S. Electrochemical detection of 4-nitrophenol based on a glassy carbon electrode modified with a reduced graphene oxide/Au nanoparticle composite. Analytical Methods. 2013; 5(20): 5508-5514.

[184]Jiao XX, Luo HQ, Li NB. Fabrication of graphene-gold nanocomposites by electrochemical co-reduction and their electrocatalytic activity toward 4-nitrophenol oxidation. Journal of Electroanalytical Chemistry. 2013; 691: 83-89.

[185]Zhang W, Chang J, Chen J, Xu F, Wang F, Jiang K, et al. Graphene-Au composite sensor for electrochemical detection of para-nitrophenol. Research on Chemical Intermediates. 2012; 38(9): 2443-2455.

[186]Vilian ATE, Choe SR, Giribabu K, Jang S-C, Rohc C, Huh YS, et al. Pd nanospheres decorated reduced graphene oxide with multi-functions: Highly efficient catalytic reduction and ultrasensitive sensing of hazardous 4-nitrophenol pollutant. Journal of Hazardous Materials. 2017; 333: 54-62.

[187]Zaidi SA, Shin JH. A novel and highly sensitive electrochemical monitoring platform for 4-nitrophenol on $\mathrm{MnO}_{2}$ nanoparticles modified graphene surface. RSC Advances. 2015; 5(108): 88996-89002.

[188]Haldorai Y, Giribabu K, Hwang S-K, Kwak CH, Huh YS, Han Y-K. Facile synthesis of $\alpha-\mathrm{MnO}_{2}$ nanorod/ graphene nanocomposite paper electrodes using a 3D precursor for supercapacitors and sensing platform to detect 4-nitrophenol. Electrochimica Acta. 2016; 222: 717-727.

[189]Alam MK, Rahman MM, Abbas M, Torati SR, Asiri AM, Kim D, et al. Ultra-sensitive 2-nitrophenol detection based on reduced graphene oxide/ZnO nanocomposites. Journal of Electroanalytical Chemistry. 2017; 788: 66-73. 
[190]Ahmad K, Mohammad A, Mathur P, Mobin SM. Preparation of $\mathrm{SrTiO}_{3}$ perovskite decorated rGO and electrochemical detection of nitroaromatics. Electrochimica Acta. 2016; 215: 435-446.

[191]Lu D, Zhang Y, Wang L, Lin S, Wang C, Chen X. Sensitive detection of acetaminophen based on $\mathrm{Fe}_{3} \mathrm{O}_{4}$ nanoparticles-coated poly(diallyldimethylammonium chloride)-functionalized graphene nanocomposite film. Talanta. 2012; 88: 181-186.

[192]Liu Z, Ma X, Zhang H, Lu W, Ma H, Hou S. Simultaneous determination of nitrophenol isomers based on $\beta$-cyclodextrin functionalized reduced graphene oxide. Electroanalysis. 2012; 24(5): 1178-1185.

[193]Liu J, Chen Y, Guo Y, Yang F, Cheng F. Eectrochemical sensor for o-nitrophenol based on $\beta$-cyclodextrin functionalized graphene nanosheets. Journal of Nanomaterials. 2013; 2013: 1-6.

[194]Yanga L, Zhao H, Li Y, Li C-P. Electrochemical simultaneous determination of hydroquinone and p-nitrophenol based on host-guest molecular recognition capability of dual-cyclodextrin functionalized Au@graphene nanohybrids. Sensors and Actuators B: Chemical. 2015; 207(Part A): 1-8. 